\title{
The nanosilica hazard: another variable entity
}

\author{
Dorota Napierska ${ }^{1 \dagger}$, Leen CJ Thomassen ${ }^{2 \dagger}$, Dominique Lison ${ }^{3}$, Johan A Martens ${ }^{2}$, Peter H Hoet ${ }^{1 *}$
}

\begin{abstract}
Silica nanoparticles (SNPS) are produced on an industrial scale and are an addition to a growing number of commercial products. SNPs also have great potential for a variety of diagnostic and therapeutic applications in medicine. Contrary to the well-studied crystalline micron-sized silica, relatively little information exists on the toxicity of its amorphous and nano-size forms. Because nanoparticles possess novel properties, kinetics and unusual bioactivity, their potential biological effects may differ greatly from those of micron-size bulk materials. In this review, we summarize the physico-chemical properties of the different nano-sized silica materials that can affect their interaction with biological systems, with a specific emphasis on inhalation exposure. We discuss recent in vitro and in vivo investigations into the toxicity of nanosilica, both crystalline and amorphous. Most of the in vitro studies of SNPs report results of cellular uptake, size- and dose-dependent cytotoxicity, increased reactive oxygen species levels and pro-inflammatory stimulation. Evidence from a limited number of in vivo studies demonstrates largely reversible lung inflammation, granuloma formation and focal emphysema, with no progressive lung fibrosis. Clearly, more research with standardized materials is needed to enable comparison of experimental data for the different forms of nanosilicas and to establish which physico-chemical properties are responsible for the observed toxicity of SNPS.
\end{abstract}

\section{Introduction}

Over the past decade, the definition of nanoparticles has been controversial. Nanoparticles are commonly defined as objects with a diameter less than $100 \mathrm{~nm}$, but no clear size cut-off exists, and this usual boundary does not appear to have a solid scientific basis. Other definitions of nanoparticles have been proposed, and the most recent proposal [1] is based on surface area rather than size (a nanoparticle should have specific surface area > $60 \mathrm{~m}^{2} / \mathrm{cm}^{3}$ ), thus reflecting the critical importance of this parameter in governing the reactivity and toxicity of nanomaterials. Physico-chemical properties that may be important in understanding the toxic effects of nanomaterials include primary particle size, agglomeration/ aggregation state, size distribution, shape, crystal structure, chemical composition, surface chemistry, surface charge, and porosity. Aspects of these properties have been discussed in several reviews of nanotoxicology [2-4].

Silica is the common name for materials composed of silicon dioxide $\left(\mathrm{SiO}_{2}\right)$ and occurs in crystalline and

\footnotetext{
* Correspondence: peter.hoet@med.kuleuven.be

+ Contributed equally

'Unit of Lung Toxicology, Katholieke Universiteit Leuven, Herestraat 49, 3000 Leuven, Belgium

Full list of author information is available at the end of the article
}

amorphous forms. Crystalline silica exists in multiple forms. Quartz, and more specifically $\alpha$-quartz is a widespread and well-known material. Upon heating, $\alpha$-quartz is transformed into $\beta$-quartz, trydimite and cristobalite. Porosil is the family name for porous crystalline silica. Quartz exists in natural and synthetic forms, whereas all porosils are synthetic. Amorphous silica can be divided into natural specimens (e.g., diatomaceous earth, opal and silica glass) and human-made products.

The application of synthetic amorphous silica, especially silica nanoparticles (SNPs), has received wide attention in a variety of industries. SNPs are produced on an industrial scale as additives to cosmetics, drugs, printer toners, varnishes, and food. In addition, nanosilica is being developed for a host of biomedical and biotechnological applications such as cancer therapy, DNA transfection, drug delivery, and enzyme immobilization [5-9]. Barik et al. [10] recently reviewed the impact of nanosilica on basic biology, medicine, and agro-nanoproducts. With the growing commercialization of nanotechnology products, human exposure to SNPs is increasing, and many aspects related to the size of these nanomaterials have raised concerns about safety [11]. Until recently, most research has focused on silica particles 0.5 to $10 \mu \mathrm{m}$, mainly in crystalline forms, but nanosilica may have different toxicological properties as
C Biomed Central

(c) 2010 Napierska et al; licensee BioMed Central Ltd. This is an Open Access article distributed under the terms of the Creative Commons Attribution License (http://creativecommons.org/licenses/by/2.0), which permits unrestricted use, distribution, and reproduction in any medium, provided the original work is properly cited. 
compared with larger particles. The unique physicochemical properties of nano-sized silica that make them attractive for industry may present potential hazards to human health, including an enhanced ability to penetrate intracellular targets in the lung and systemic circulation.

Biocompatibility is a critical issue for the industrial development of nanoparticles [12,13]. Even though no acute cytotoxicity has been observed or reported, the uptake of the nanoparticles by cells may eventually lead to perturbation of intracellular mechanisms. The ability of silica-coated nanomaterials to penetrate the bloodbrain barrier also strongly suggests that extensive studies are required to clarify the potential chronic toxicity of these materials [14].

A number of SNPs have recently been shown to cause adverse health effects in vitro and in vivo (discussed later in this review). However, most of the studies have used poorly characterized particles in terms of their composition and physico-chemical properties. The distinct physico-chemical properties of nanoparticles indeed determine their interaction with the cell/within the cell, and even subtle differences in such properties can modulate the toxicity and modes of action. The results of toxicity studies then become difficult to interpret and compare, and, as a result, drawing appropriate conclusions is nearly impossible. Although SNPs could certainly provide benefits to society, their interaction with biological systems and potential toxic effects must be carefully addressed.

In this review, we discuss silica materials with a special attention to the physico-chemical properties that can affect their potential interaction with biological systems. We aim to provide an overview of the recent in vitro and in vivo investigations of the toxicity of nanosilica, both in crystalline and amorphous forms, rather than review the toxicity of micron-sized silica and quartz. A summary of the present knowledge on the potential toxic effects of nano-sized silica particles is needed, because their toxicological pattern appears distinct from that of micron-sized silica particles.

\section{Synthesis \& Characterization of Silica Materials} Classification of natural and synthetic silica materials "Silica" is the name given to materials with the chemical formula of silicon dioxide, $\mathrm{SiO}_{2}$. Silicas can be amorphous or crystalline, porous or non-porous (dense), anhydrous or hydroxylated [15], regardless of their natural or synthetic nature. In a silica material, the silicon atom is in tetrahedral coordination with 4 oxygen atoms. Theoretically, an infinite variety of 3-D-ordered structures can be built from oxygen-sharing silicate tetrahedra. The number of known crystalline silica materials is limited, which leaves much room for research and development. In amorphous silica, the tetrahedra are randomly connected.

In nature, amorphous silica can have different origins. Silica can be condensed from vapors emitted in volcanic eruptions. Natural silica can also be deposited from supersaturated natural water or polymerized in living organisms (biogenic silica). These amorphous biogenic silicas can be found as isolated particles, skeletal structures or surface elements in different living organisms. Many microcrystalline silica minerals such as flint, chert and chalcedony are derived from biogenic silica after crystallization by compaction. Kieselguhr (diatomaceous earth) occurs at various stages of transformation [15] and therefore often exhibits both crystalline and amorphous silica constituents.

\section{Physico-chemical characteristics of synthetic silica materials related to toxicity}

The silica materials presenting a toxicological hazard to human health are mainly synthetic materials and natural quartz. The physico-chemical properties of silica materials largely depend on the synthetic procedures used for their preparation. Therefore, we will briefly discuss silica synthesis processes.

\section{Silica synthesis}

Silica is mainly synthesized from an aqueous solution, with dissociated monomeric silicic acid, $\mathrm{Si}(\mathrm{OH})_{4}$, or from a vapor of a silicon compound such as silicon tetrachloride.

Waterglass is a concentrated alkaline sodium silicate solution with anhydrous composition corresponding to $\mathrm{Na}_{2} \mathrm{SiO}_{3}$. It is the most common reagent for silica production in aqueous solution. Waterglass is a sodium salt of silicic acid that forms silicic acid upon acidification. When the concentration of $\mathrm{Si}(\mathrm{OH})_{4}$ exceeds about $2.10^{-3} \mathrm{M}$, condensation to polysilicic acids (Figure 1 ) occurs, thus leading to the formation of colloidal silica particles [15].

The polymerization and the formation of silica can be represented as follows:

$$
\begin{aligned}
& {\left[\mathrm{Si}_{\mathrm{n}} \mathrm{O}_{2 \mathrm{n}-\mathrm{nx} / 2}(\mathrm{OH})_{\mathrm{nx}}\right]+\mathrm{m} \mathrm{Si}(\mathrm{OH})_{4} \rightarrow} \\
& {\left[\mathrm{Si}_{\mathrm{n}+\mathrm{m}} \mathrm{O}_{2 \mathrm{n}-\mathrm{nx} / 2+2 \mathrm{~m}(2-\mathrm{p})}(\mathrm{OH})_{\mathrm{nx}+4(\mathrm{~m}-\mathrm{p})}\right]+2 \mathrm{pm} \mathrm{H}_{2} \mathrm{O}} \\
& \text { Where: }
\end{aligned}
$$

$\mathrm{n}=$ number of silicon atoms in a polysilicic acid molecule or particle,

$\mathrm{x}=$ number of $\mathrm{OH}$ groups per silicon atom in the polymer $(0 \leq x \leq 3)$,

$\mathrm{m}=$ number of monomeric silicic acid molecules added to the polymer, and

$\mathrm{p}=$ fraction of the hydroxyl groups per monomeric silicic acid molecule that are converted to water during the polymerization reaction [15]. 
<smiles>O[Si](O)(O)O</smiles><smiles>O[Si](O)(O)O</smiles><smiles>C[13CH]=O</smiles><smiles>O[Si](O)(O)O[Si](O)(O)O</smiles>

Figure 1 Polymerization of silicic acid molecules through formation of siloxane bond and water.

Amorphous silica particles are formed by polymerization of monomers in the aqueous solution supersaturated with silicic acid. Various silica materials are produced in liquid phase processes (Figure 2).

Colloidal silica or silica sol is most often produced in a multi-step process in which the alkaline silicate solution is partially neutralized with a mineral acid. Alternatively, this $\mathrm{pH}$ neutralization can be achieved by electrodialysis. The resulting silica suspension is stabilized by $\mathrm{pH}$ adjustment. Finally a solid concentration up to $50 \mathrm{wt} \%$ is reached by water evaporation. Silica sol nanoparticles show a perfect spherical shape and identical size as a result of extensive Ostwald ripening [15]. Stöber silica sol is prepared by controlled hydrolysis and condensation of tetraethylorthosilicate (TEOS) in ethanol to which catalytic amounts of water and ammonia are added. The Stöber procedure can be used to obtain monodisperse spherical amorphous silica particles with tunable size and porosity [16].

Silica gel is obtained by destabilizing silica sol. Silica gel is an open 3-D network of aggregated sol particles. The pore size is related to the size of the original silica sol particles composing the gel.

Precipitated silica is formed when a sol is destabilized and precipitated.

Ordered mesoporous silica is obtained by a supramolecular assembly of silica around surfactant micelles. Typical surfactant molecules are amphiphilic polymers such as tribloc copolymers or quaternary alkylammonium compounds. These organic supramolecular templates are evacuated from the mesopores, typically via a

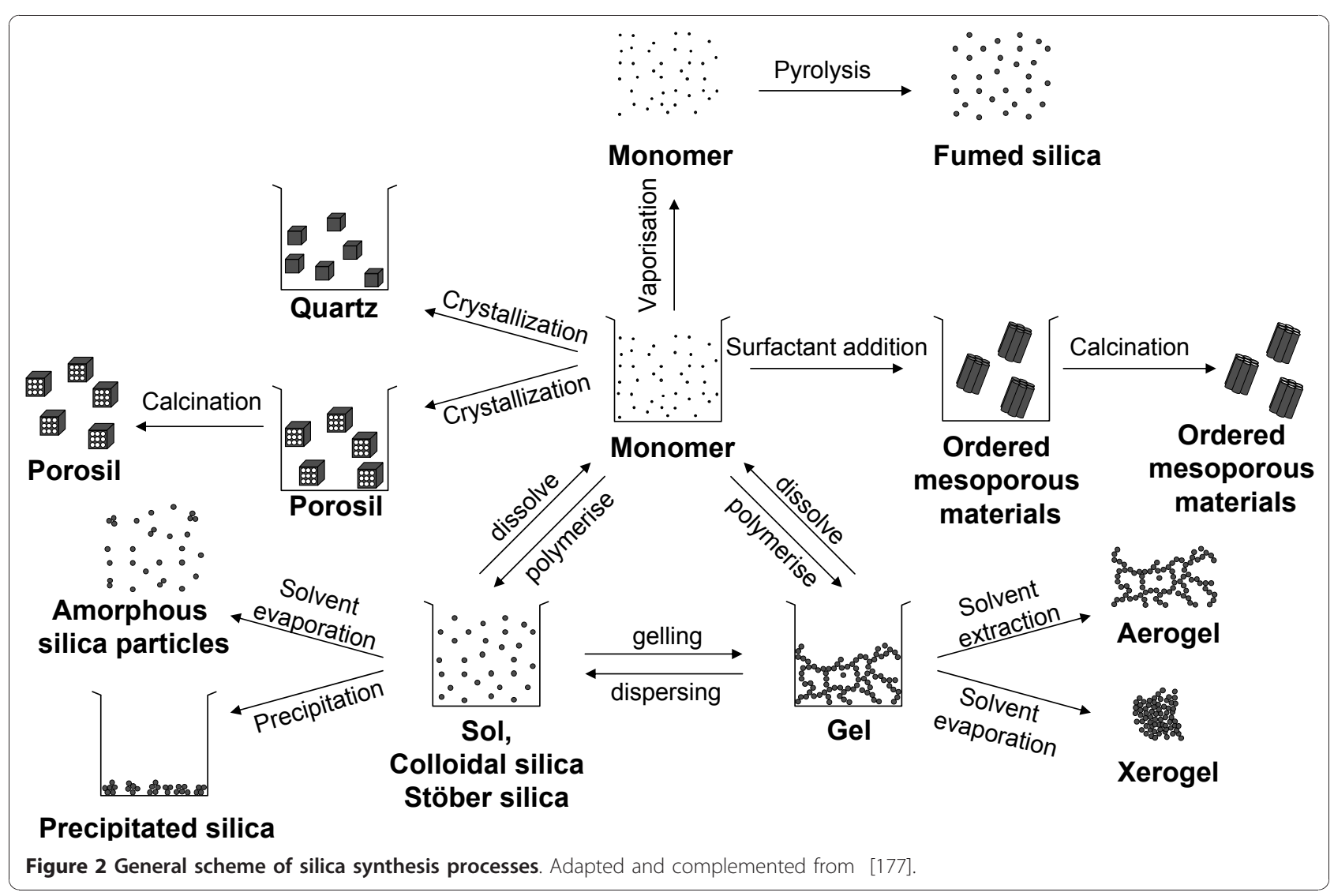


calcination step. Calcination is a controlled combustion process leading to oxidation and decomposition of the template molecules into small volatile products such as $\mathrm{NO}_{\mathrm{x}}, \mathrm{CO}_{2}$ and $\mathrm{H}_{2} \mathrm{O}$, which can leave the pores. The diameter of the mesopores $(2-50 \mathrm{~nm})$ is determined by the type of surfactant applied $[17,18]$.

A completely different synthesis route of amorphous silica starts from $\mathrm{SiCl}_{4}$ in the vapor phase. Silicon tetrachloride is oxidized in a hydrogen flame at temperatures exceeding $1000^{\circ} \mathrm{C}$ and polymerized into amorphous non-porous SNPs. This nanopowder has very low bulk density and high specific surface area, typically 200 to $300 \mathrm{~m}^{2} / \mathrm{g}$. This material is called pyrogenic or fumed silica, referring to the special synthesis conditions [15].

The synthesis of dense crystalline silica such as quartz from aqueous solution is a slow process requiring heating the solution to accelerate the formation process in a so-called hydrothermal synthesis [15]. Alternatively, under high pressure, amorphous silica can be transformed to crystalline material by microcrystallization. The appearance of quartz ranges from macroscopic crystals to microcrystalline powders. Large crystals are grown at high temperature and pressure in industry. Smaller quartz crystals are conveniently obtained by grinding large crystals. Alpha-quartz is formed under moderate temperature and pressure conditions and is the most abundant form of quartz. At temperatures exceeding $573^{\circ} \mathrm{C}, \alpha$-quartz can transform into $\beta$-quartz [19]. At atmospheric pressure and temperatures higher than $870^{\circ} \mathrm{C}$, quartz is transformed into tridymite and at temperatures more than $1470^{\circ} \mathrm{C}$ into cristobalite $[15,20]$. These high-temperature polymorphs of quartz have the same elemental composition but a different crystal structure and can persist metastably at lower temperatures.

Dense and porous crystalline materials can be distinguished by framework density. The framework density is conveniently defined as the number of tetrahedrally coordinated atoms (T-atoms) per $\mathrm{nm}^{3}$. For dense structures, such as quartz, tridymite and cristobalite, values of 22 to $29 \mathrm{~T}$-atoms $/ \mathrm{nm}^{3}$ are common, whereas for porosils belonging to the zeolite material family, as few as 12.1 T-atoms $/ \mathrm{nm}^{3}$ are present [21]. The framework structure of a porosil is denoted with a 3-letter code. Descriptions are available in the Atlas of Zeolite Framework Types [22].

Porosils are crystallized in aqueous media in the presence of organic molecules that act as porogens or template molecules defining the size and shape of the pores. Their evacuation is typically achieved through calcination. Among the porosils are clathrasils and zeosils $[23,24]$. Zeosils have cages with windows or channels of a sufficiently free dimension to allow molecules to diffuse in and out, a property known as molecular sieving [25].
Clathrasils have cages with windows that are delineated with a 6-membered ring of $\mathrm{SiO}$ units, thus presenting a free aperture of barely $0.28 \mathrm{~nm}$. Even a molecule as small as oxygen has no access to the cavities of a clathrasil. The organic template molecules engaged in the crystallization of a clathrasil cannot be removed easily from the pores $[23,24]$.

When heated above $1700^{\circ} \mathrm{C}$, any type of silica (amorphous or crystalline) melts. During cooling, the disordered structure is solidified, and a dense amorphous silica glass or vitreous silica is formed [15].

\section{Physico-chemical properties}

The properties of silica materials considered essential for their potential toxicity are crystallinity, particle size and morphology, porosity, chemical purity, surface chemistry and solubility [26]. An overview of the properties of silica materials involved in silica toxicity is provided in Table 1.

\section{Crystallinity}

In crystalline structures such as quartz and porosils, the arrangement of atoms is ordered in all dimensions. According to the International Union of Pure and Applied Chemistry (IUPAC), the atoms must be arranged periodically with long-range order (at least 10 repeats in all directions) and produce sharp maxima in a diffraction experiment to observe $x$-ray diffraction (XRD) crystallinity [27]. The threshold for observing crystallinity depends on the unit cell size (size of the repeated unit in a crystal). For materials with large unit cells, such as porosils, the minimum particle size required is about 10 nanometers to observe a distinct, sharp XRD pattern. Amorphous silica may present some short-range order but lacks long-range order in 3 dimensions and does not exhibit a sharp XRD pattern. Of note, the surface of a crystal represents a discontinuity that can be seen as a defect. With the presence of a less-structured or even partially amorphous rim, crystals may behave like amorphous particles. Thus, particles with an ordering at limited-length scales or with amorphous regions may be classified as amorphous.

\section{Particle size and morphology}

Nanoparticles are obtained by direct synthesis of silica sol [15] or by crystallization of nano-sized crystals of quartz or porosils [25]. The particle size is determined by the synthesis parameters. Amorphous silica sol particles tend to adopt the spherical shape so as to reach a minimum of interfacial surface area. The particle size of commercial silica sols prepared from sodium silicate is from 10 to $25 \mathrm{~nm}$ (Figure 3 left). Sols with larger primary particles can be prepared from TEOS by Stöber synthesis, for example (Figure 3 middle). Grinding and milling processes reduce particle size. These techniques are most often applied to quartz, silica gel and vitreous 
Table 1 Overview of silica materials and relevant properties

\begin{tabular}{|c|c|c|c|c|c|c|c|c|}
\hline Material & $\begin{array}{l}\text { Nature } \\
\text { of } \\
\text { product }\end{array}$ & Crystallinity & Particle size & Porosity & Polarity & Purity & Applications & Ref \\
\hline $\begin{array}{l}\text { Colloidal } \\
\text { silica }\end{array}$ & Sol & Amorphous & $1-1000 \mathrm{~nm}$ & Dense & Hydrophillic & $\begin{array}{l}\text { Very } \\
\text { high }\end{array}$ & Binders, ink & {$[15]$} \\
\hline Stober silica & Sol & Amorphous & $10-1000 \mathrm{~nm}$ & Tunable porosity & Hydrophillic & $\begin{array}{l}\text { Very } \\
\text { high }\end{array}$ & Research & {$[16]$} \\
\hline $\begin{array}{l}\text { Precipitated } \\
\text { silica }\end{array}$ & Powder & Amorphous & $\begin{array}{l}5-6 \mathrm{~nm} \text { primary particles precipitated } \\
\text { to } 500 \mathrm{~nm}-50 \mu \mathrm{m} \text { aggregates }\end{array}$ & Tunable porosity & Hydrophillic & $\begin{array}{l}\text { Very } \\
\text { high }\end{array}$ & $\begin{array}{l}\text { Filler } \\
\text { and } \\
\text { performance } \\
\text { additive }\end{array}$ & [15] \\
\hline Silica gel & Powder & Amorphous & $\begin{array}{l}0.5-5 \mathrm{~nm} \text { primary particles gelled } \\
\text { to networks and milled to } 500 \mu \mathrm{m} \text { - } \\
6 \mathrm{~mm} \text { aggregates }\end{array}$ & $\begin{array}{l}\text { Tunable, void } \\
\text { spaces between } \\
\text { primary particles }\end{array}$ & Hydrophillic & $\begin{array}{l}\text { Very } \\
\text { high }\end{array}$ & $\begin{array}{l}\text { Dessicant, } \\
\text { filler } \\
\text { and } \\
\text { performance } \\
\text { additive }\end{array}$ & {$[15]$} \\
\hline $\begin{array}{l}\text { Mesoporous } \\
\text { silica }\end{array}$ & Powder & Amorphous & $\begin{array}{l}50 \text { - } 1000 \mathrm{~nm} \text {, aggregated because } \\
\text { of calcinations }\end{array}$ & Mesoporous & Hydrophobic & $\begin{array}{l}\text { Very } \\
\text { high }\end{array}$ & $\begin{array}{l}\text { Drug delivery, } \\
\text { catalysis, } \\
\text { imaging }\end{array}$ & [8] \\
\hline $\begin{array}{l}\text { Pyrogenic } \\
\text { silica (fumed } \\
\text { silica) } \\
\end{array}$ & Powder & Amorphous & $\begin{array}{l}2-50 \mathrm{~nm} \text { primary particles fused to 1- } \\
250 \mu \mathrm{m} \text { aggregates }\end{array}$ & $\begin{array}{l}\text { Void spaces } \\
\text { between primary } \\
\text { particles }\end{array}$ & Hydrophobic & $\begin{array}{l}\text { Very } \\
\text { high }\end{array}$ & $\begin{array}{l}\text { Tickner, } \\
\text { performance } \\
\text { additive }\end{array}$ & {$[15]$} \\
\hline $\begin{array}{l}\text { Vitreous } \\
\text { silica (fused } \\
\text { silica glass) }\end{array}$ & Powder & Amorphous & $50-2000 \mu \mathrm{m}$ & Dense & $\begin{array}{l}\text { Hydrophobic } \\
\text { (grinded: } \\
\text { hydrophilic) }\end{array}$ & Variable & Glass & {$[15,19]$} \\
\hline Quartz & Powder & Crystalline & $50 \mathrm{~nm}$ - several $\mu \mathrm{m}$ & Dense & $\begin{array}{l}\text { Hydrophobic/ } \\
\text { (grinded: } \\
\text { hydrophilic) }\end{array}$ & Variable & $\begin{array}{l}\text { Geologic } \\
\text { mineral, } \\
\text { Piezoelectricity }\end{array}$ & {$[19,20]$} \\
\hline Cristobalite & Powder & Crystalline & $1 \mu \mathrm{m}$ - several $\mathrm{cm}$ & Dense & Hydrophobic & Variable & $\begin{array}{l}\text { Geologic } \\
\text { mineral }\end{array}$ & {$[20]$} \\
\hline $\begin{array}{l}\text { Zeosils } \\
\text { (porosil) }\end{array}$ & Powder & Crystalline & $0.05-5000 \mu \mathrm{m}$ & $\begin{array}{l}\text { Porous } \\
\text { Pore diameter: } \\
0.4-1.2 \mathrm{~nm}\end{array}$ & $\begin{array}{l}\text { Hydrophillic/ } \\
\text { hydrophobic }\end{array}$ & $\begin{array}{l}\text { Very } \\
\text { high }\end{array}$ & Adsorbent & {$[25]$} \\
\hline $\begin{array}{l}\text { Clathrasils } \\
\text { (porosil) }\end{array}$ & Powder & Crystalline & $0.5-5000 \mu \mathrm{m}$ & $\begin{array}{l}\text { Porous } \\
\text { Pore diameter: } \\
0.2-0.3 \mathrm{~nm}\end{array}$ & $\begin{array}{l}\text { Hydrophillic/ } \\
\text { hydrophobic }\end{array}$ & $\begin{array}{l}\text { Very } \\
\text { high }\end{array}$ & Gas separation & {$[24]$} \\
\hline $\begin{array}{l}\text { Diatomeus } \\
\text { earth, } \\
\text { kieselguhr }\end{array}$ & Powder & $\begin{array}{l}\text { Amorphous, } \\
\text { partially } \\
\text { crystalline }\end{array}$ & $5-120 \mu \mathrm{m}$ & Dense & $\begin{array}{l}\text { Hydrophillic/ } \\
\text { hydrophobic }\end{array}$ & $\begin{array}{l}\text { Low } \\
(90 \%)\end{array}$ & $\begin{array}{l}\text { Filter, filling } \\
\text { material }\end{array}$ & {$[15]$} \\
\hline
\end{tabular}

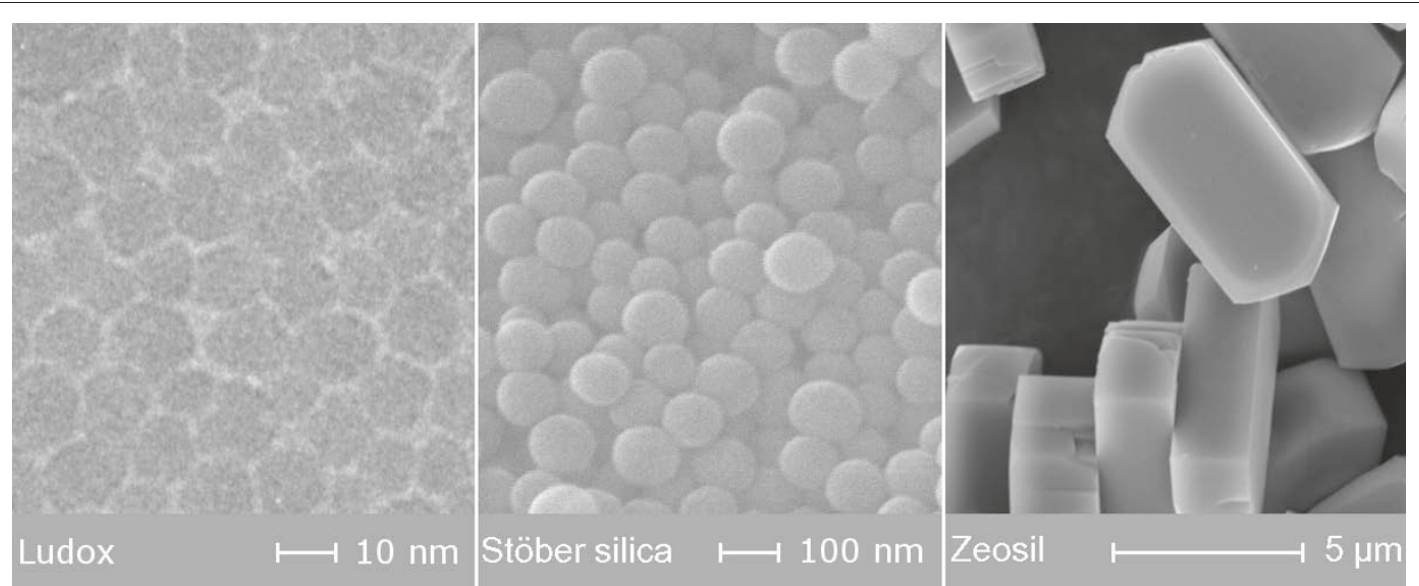

Figure 3 Electron microscopy images of Stöber silica sol particles (left) and MFI type zeosil (right). 
silica. The obtained products generally have a broad size distribution.

Crystalline particles exhibit crystal planes at the surface, and the morphology of the crystalline nanoparticles depends on the crystal class such as cubic, hexagonal, tetragonal, and orthorhombic (Figure 3 right). For all nanomaterials, in aqueous environment, the primary nano-sized silica particles tend to form aggregates.

\section{Porosity}

According to IUPAC [28], pores are classified according to their diameter into micropores $(<2 \mathrm{~nm})$, mesopores $(2-50 \mathrm{~nm})$ and macropores $(>50 \mathrm{~nm})$. Amorphous sol particles can be microporous or non-porous (dense). The porosity of Stöber silica can be tuned by adapting the synthesis parameters: decreasing the ratio of water to TEOS promotes particle growth by aggregating smaller sub-particles, thus leading to rough particle surfaces with micropores. In contrast, smooth particle surfaces are obtained with conditions of high ratio of water to TEOS [29]. Silica gel is a powder with particle size in the micrometer range or larger and is, typically, mesoporous.

Zeosils and clathrasils have characteristic pores and cages in the micropore size range, depending on framework topology. Examples of porosil frameworks are shown in Figure 4 [22].

When the silica is presented as a nanopowder, porosity can be an intrinsic and extrinsic characteristic: stapling of the elementary nanoparticles gives rise to an interparticle porosity, which often is difficult to distinguish from the intrinsic intraparticle porosity, especially when dealing with mesoporosity.

\section{Hydrophilic-hydrophobic properties}

The hydrophilicity of a silica material increases with the number of silanols, or silicon-bonded hydroxyl groups, capable of forming hydrogen bonds with physical water molecules. The chemical formula of silica is represented

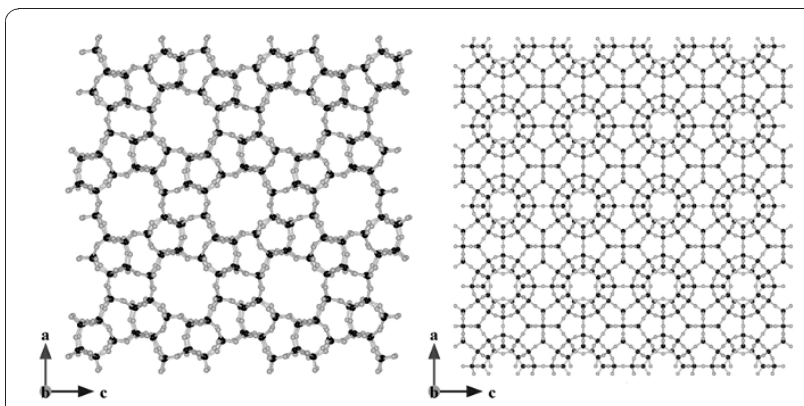

Figure 4 Atomic representation of (left) a zeosil with microporous channels (MFI type) and (right) clathrasil with a denser framework (SOD type). Black and gray circles represent silicon and oxygen atoms, respectively. Figure made with Vesta 2.0.3 [178] with unit cell coordinates from [22].

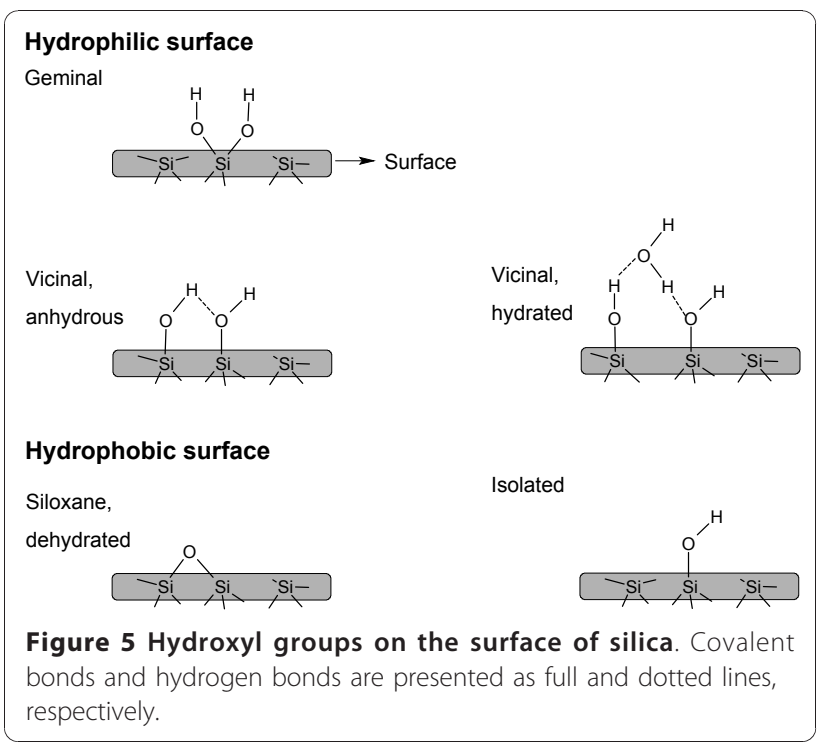

as $\mathrm{SiO}_{2} \cdot \mathrm{xH}_{2} \mathrm{O}$, in which water represents chemical water contained in silanol groups present on the surface of the silica material. These water molecules are not to be confused with crystal water, such as that present in many inorganic salt crystals. The surface chemistry of silica is depicted in Figure 5. Vicinal hydroxyl groups (one hydroxyl group per tetrahedron) located at mutual distances smaller than $3 \mathrm{~nm}$ are engaged in hydrogen bonding. Geminal hydroxyls (2 hydroxyl groups per tetrahedron) are considered to occur in minor concentrations. Isolated silanols are positioned too far apart to be engaged in hydrogen bonding. Because of the differing chemistry of these 3 types of silanol groups, they are not all equivalent in their adsorption behavior or chemical reactivity. Vicinal hydroxyls interact strongly with water molecules and are responsible for the excellent water adsorption properties of silica, which are exploited in industrial gas drying operations, for example.

The reported concentration of hydroxyl groups per square nanometer on the surface of amorphous silica ranges from 4 to $5 \mathrm{OH} / \mathrm{nm}^{2}$ [12]. As compared with amorphous silica, the crystalline forms of silica generally contain a lower concentration of surface hydroxyl groups [15]. Hydrogen-bonded water molecules are removed when silica is heated at $170^{\circ} \mathrm{C}$ under atmospheric pressure or at room temperature under vacuum.

Colloidal silica, precipitated silica and ordered mesoporous silica and silica gel are hydrophilic because of their high concentration of silanols. Silicagel, for example, can adsorb water in quantities up to $100 \%$ of its proper weight.

Porosils typically are hydrophobic because they lack silanols in the pores of their framework. Silica produced at high temperature, such as pyrogenic and vitreous 
silica, or calcined at temperatures exceeding $800^{\circ} \mathrm{C}$, is almost entirely dehydroxylated. In a dehydroxylation reaction, neighboring silanol groups are condensed into siloxane bonds (Figure 5 bottom) and water molecules. Some isolated silanol groups may persist on the surface [15]. Because hydrogen bonding on siloxanes is unfavorable, dehydroxylated silica is hydrophobic. Grinding of hydrophobic bulk materials such as quartz and vitreous silica induces silicon and oxygen radicals and surface charges. These charges increase the hydrophilic surface $[19,30]$.

\section{Solubility}

The dissolution and precipitation of silica in water chemically involves hydrolysis and condensation reactions, respectively, catalyzed by $\mathrm{OH}^{-}$ions (Figure 1).

For micrometer-sized nonporous amorphous silica, the equilibrium concentrations of $\mathrm{Si}(\mathrm{OH})_{4}$ at $25^{\circ} \mathrm{C}$ in water corresponds to $70 \mathrm{ppm}$ at $\mathrm{pH}$ 7. The silica solubility depends on the surface curvature of the (nano)particles. SNPs and nanoporous silica show enhanced equilibrium solubility, of 100-130 ppm [12]. According to Vogelsberger et al. [31], the solubilization of amorphous SNPs in physiological buffer at $25^{\circ} \mathrm{C}$ is accelerated because of the large surface area exposed. The solubility equilibrium is reached only after 24 to $48 \mathrm{~h}$. Crystalline silica such as quartz has a much lower equilibrium solubility, of 6 ppm [15].

In summary, when dealing with silica, the physicochemical properties such as amorphous versus crystalline nature, porosity, particle size and degree of hydroxylation must be specified. An overview of silica materials described in the scientific literature and in the research and development environment is provided in Table 1.

\section{Toxicity Of Silica \\ Background \\ Health effects of silica and epidemiological studies}

Until recently, toxicological research into silica particles focused mainly on "natural" crystalline silica particles of 0.5 to $10 \mu \mathrm{m}$ (coarse or fine particles). This research was/is fed by the clear association of occupational inhalation exposure and severe health effects, mainly on the respiratory system. The typical lung reaction induced by chronic inhalation of crystalline silica is silicosis, a generally progressive fibrotic lung disease (pneumoconiosis), exemplified by the development of silicotic nodules composed of silica particles surrounded by whorled collagen in concentric layers, with macrophages, lymphocytes, and fibroblasts in the periphery. Epidemiologic studies have found that silicosis may develop or progress even after occupational exposure has ended; therefore, above a given lung burden of particles, silicosis was suggested to progress without further exposure [32-34].
Calvert et al. [35] recently reported an association of crystalline silica (mainly quartz) exposure and silicosis, as well as lung cancer, chronic obstructive pulmonary disease (COPD), and pulmonary tuberculosis. The carcinogenicity of quartz and cristobalite has been shown in several epidemiological studies [36-38]. In 1997, the International Agency for Research on Cancer (IARC) classified some crystalline silica polymorphs (quartz and cristobalite) in group 1 (sufficient evidence for the carcinogenicity to experimental animals and to humans), whereas amorphous silica (silicon dioxide without crystalline structure) was classified in group 3 (inadequate evidence for carcinogenicity) [39]. This classification has recently been confirmed [40]. Checkoway and Franzblau [41] reviewed occupational epidemiologic literature on the interrelations among silica exposure, silicosis and lung cancer and concluded that the appearance of silicosis is not necessarily required for the development of silica-associated lung cancer. Hnizdo and Vallyathan [42] suggested that chronic exposure to levels of crystalline silica dust, which does not cause disabling silicosis, may cause chronic bronchitis, emphysema, and/or small airway disease leading to airflow obstruction, even in the absence of radiological evidence of silicosis. Evidence has linked silica exposure to various autoimmune diseases (systemic sclerosis, rheumatoid arthritis, lupus, chronic renal disease), as reviewed by Steenland and Goldsmith [43]. A study by Haustein et al. [44] reported on silica-induced (silica dust) scleroderma.

Amorphous silica has been far less studied than has the crystalline form [39]. Warheit [45] briefly described the inhalation toxicity data related to amorphous silica particulates and concluded that some forms of amorphous silica are more potent in producing pulmonary effects as compared to others. He also emphasized the great need for adequate toxicological testing of many of these amorphous silicates given their importance in commerce and widespread potential for exposure. Workers exposed to precipitated or fumed silica did not exhibit pneumoconiosis $[46,47]$, but evidence of pulmonary fibrosis was reported in workers exposed to amorphous silica dust produced as a byproduct of silicon metal production [48]. Merget et al. [49] reviewed the current knowledge of the health effects of a wide range of amorphous forms of silica in humans. The major problem in the assessment of health effects of biogenic amorphous silica is its contamination with crystalline silica. This problem applies particularly to the well-documented pneumoconiosis among diatomaceousearth workers. Although the data are limited, a risk of chronic obstructive bronchitis disease, COPD or emphysema cannot be excluded [49]. Animal inhalation studies involving synthetic amorphous silica (colloidal silica, fumed silica and precipitated silica) showed at least 
partially reversible inflammation [50,51], granuloma formation and emphysema, but no progressive fibrosis of the lungs [52,53]. However, high doses of amorphous silica may result in acute pulmonary inflammatory responses, which could conceivably trigger long-term effects, despite a low biopersistence of the particles [54]. The debate on the health effects of micron-sized crystalline or amorphous silica is beyond the scope of this article. Readers are referred to other publications [35-38,41,55-57].

\section{Mechanisms of toxic action}

As mentioned, most of the toxicological research into silica has focused on crystalline silica particles of 0.5 to $10 \mu \mathrm{m}$ (coarse or fine particles). Despite the relatively large amount of available studies, the mechanisms of crystalline silica toxicity at the cellular and molecular levels are still unclear, and whether any single mechanism underlies all the above-mentioned diseases induced by these particles is uncertain [43]. However, severe inflammation following exposure to silica particles appears to be a common initiating step [58,59].

The crucial role of reactive oxygen species (ROS) in the inflammatory, fibrogenic and carcinogenic activity of quartz is well established [60,61]. Oxidative membrane and DNA damage are considered the most important mechanisms involved in the health effects of micronsized crystalline silica. A few of the numerous reports clearly demonstrate these findings: ROS generated by the silica surface can induce cell membrane damage via lipid peroxidation that may subsequently lead to increased cellular permeability [62], perturbation of intracellular calcium homeostasis [63] and alterations in signaling pathways. Schins et al. and Fanizza et al. $[64,65]$ demonstrated that respirable quartz particles induce oxidative DNA damage in human lung epithelial cells. Li et al. $[66,67]$ demonstrated that micron-sized quartz particles induce $\mathrm{OH}$ generation through an irondependent mechanism. A close association of $\mathrm{OH}$ and iron ion concentration has been reported for amorphous silica particles [66,67]. The study of Ghiazza et al. [30] indicates that crystallinity might not be a necessary prerequisite to make a silica particle toxic; both quartz and vitreous silica showed stable surface radicals and sustained release of $\mathrm{HO}$ radicals. When tested on macrophages, vitreous silica and pure quartz showed a remarkable potency in cytotoxicity, release of nitrite and tumor necrosis factor $\alpha$ (TNF- $\alpha$ ) production, suggesting a common behavior in inducing of oxidative stress [30]. Ding et al. [68] discuss the molecular mechanisms of silica-induced lung injuries with a focus on NF-kB activation, generation of cyclooxygenase II and tumor necrosis factor $\alpha$ (TNF- $\alpha)$. The review of Castranova [69] summarizes evidence that in vitro and in vivo exposure to crystalline silica results in activation of NF-kB and AP-1 signaling pathways. In vitro and in vivo animal studies, as well as investigations in humans, strongly support the role of macrophage products in the development and progression of silicosis [70]. Such products include a large panel of cytokines [71], with TNF$\alpha$ seeming to determine the development of silicainduced pulmonary fibrosis [72]. In addition, recent evidence implicates interleukin $1 \beta$ (IL-1 $\beta$ ) and its activation by the NALP-3 inflammasome [73].

A large body of experimental work in the past 20 years has shown that 2 main factors seem to govern the hazardous nature of crystalline silica: particle surface reactivity and the form of silica [74]. Fenoglio et al. [75] evaluated these factors systematically, studying synthetic quartz samples differing only in size and shape. Cytotoxicity appeared to be primarily governed by the form of the particles and the extent of the exposed surface. Several studies indicate that the surface silanol groups are directly involved both in membranolysis [76-78] and in toxicity to alveolar cells $[79,80]$. Therefore, the distribution and abundance of silanols determines the degree of hydrophilicity (see "Physico-chemical properties of synthetic silica materials related to toxicity" described above) and seems to modulate cell toxicity $[80,81]$. Experimental work with respirable silica particles and the survey of published data by Bagchi [82] suggest that the toxicity of these particles is caused by the large amount of positive charges they carry. Ghiazza et al. [83] reported that formation of a vitreous phase at the surface of some commercial diatomaceous earth prevents the onset of oxidative stress effects. Donaldson and Borm [84] emphasized that the ability of quartz to generate ROS could be modified by a range of substances that affect the quartz surface, such as substances originating from other minerals. The authors concluded that the toxicity of quartz is not a constant entity and may vary greatly depending on the origin/constitution of the sample.

The origin/synthesis of SNPs plays a crucial role in determining the physico-chemical properties of these particles and, consequently, their potential interactions with biological systems. Surface area, surface morphology, surface energy, dissolution layer properties, adsorption and aggregation properties are relevant parameters. Depending on the manufacturing process, amorphous silica has a wide range of physico-chemical properties that determine its industrial application. Bye et al. [85] showed that the cytotoxic activity of different forms of amorphous silica does not depend on a crystalline silica component but, rather, is caused by surface charges and the morphologic features of particles. Synthetic amorphous silica has been the subject of dissolution testing with a simulated biological medium, and the silica 
dissolution rate was reported as being more rapid than the reverse precipitation rate [86]. Solubility has been defined as a key driver in the clearance mechanisms involved in amorphous silica removal from lung [87]. Warheit [45] reviewed pulmonary responses to different forms of silica and reported that cristobalite produced the greatest lung injury, quartz produced intermediate effects, and amorphous silica produced minimal effects. In terms of analytical technique, small differences in dissolution exist among these different forms of silica, and dissolution, in turn, influences pulmonary effects through the concept of persistence. In addition, components from the biological system may react with the surface of the particle. A systematic investigation of iron-containing SNPs as used in industrial fine-chemical synthesis demonstrated the presence of catalytic activity that could strongly alter the toxic action of nanoparticles [88].

On the whole, considering the great variety of silica forms, degree of crystallinity, surface state and the presence of contaminants, there is a critical need for carefully characterized standard silica samples to unravel the relationships between physico-chemical factors and toxicity, both micron- and nano-sized. The main goal of this review is to focus on the toxicity of nanosilica, which has never been properly reviewed. Moreover, nanosilica occurs mainly in amorphous forms, and the potential hazard posed by these nanomaterials cannot be simply related to, as has already been reviewed many times, studies of micron-sized crystalline materials.

\section{Silica nanoparticles}

The growing abundance and industrial applications of nanotechnology has resulted in a recent shift of toxicological research towards nanoparticles [89-94]. Ultrafine particles $(<0.1 \mu \mathrm{m})$ have been demonstrated to cause greater inflammatory responses and particle-mediated lung diseases than have fine particles $(<2.5 \mu \mathrm{m})$ per given mass [95-97]. Also, experiments involving silica have shown that nanoparticles, both ultrafine colloidal silica [98,99] and crystalline silica [99], have a greater ability to cause lung injury as compared with fine particles. Thus, the unique properties (i.e., small size and corresponding large specific surface area; cell penetrating ability) of nano-sized $\mathrm{SiO}_{2}$ are likely to impose biological effects that differ greatly from micron-scale counterparts.

\section{In vitro studies of nanosilica toxicity}

A structured summary of in vitro studies of the toxicity of SNPs can be found in Table 2.

Chen and von Mikecz [100] investigated the effects of nanoparticles on structure, function, and proteasomal proteolysis in the cell nucleus by incubating different cell lines with unlabeled and fluorescently labeled amorphous silica particles of different sizes [100]. $\mathrm{SiO}_{2}$ particles between $40 \mathrm{~nm}$ and $5 \mu \mathrm{m}$ were applied to epithelial cells in culture and observed on confocal laser scanning microscopy with differential interference contrast. Particles of all tested sizes penetrated the cytoplasm; however, nuclear localization was observed exclusively in cells treated with $\mathrm{SiO}_{2}$ nanoparticles between 40 and $70 \mathrm{~nm}$. Fine and coarse $\mathrm{SiO}_{2}$ particles $(0.2-5 \mu \mathrm{m})$ were exclusively located in the cytoplasm and accumulated around the nucleus, forming nuclear indentations. The uptake of SNPs in the nucleus induced aberrant clusters of topoisomerase I and protein aggregates in the nucleoplasm - the former inhibiting replication, transcription, and cell proliferation - without altering cell viability. Cells treated with fine $(0.5 \mu \mathrm{m})$ or coarse $(5 \mu \mathrm{m}) \mathrm{SiO}_{2}$ particles had the same replication and transcription activity as that of untreated control cells [100].

Jin et al. [101] investigated the potential toxicity of luminescent amorphous SNPs $(50 \mathrm{~nm})$ in freshly isolated rat alveolar macrophage cells and human lung epithelial cells (A549 cells). The SNPs penetrated the cells but were not detected in the nuclear region and did not cause significant toxic effects at the molecular and cellular levels below a concentration of $0.1 \mathrm{mg} / \mathrm{ml}$.

Lin et al. [102] investigated the cytotoxicity of amorphous (colloidal) SNPs (15 and $46 \mathrm{~nm}$ ) in cultured human alveolar epithelial cells (A549 cells). Cell viability decreased in a time- and dose-dependent manner (down to $100 \mu \mathrm{g} / \mathrm{ml}$ ), and nanoparticles of both sizes were more cytotoxic than were fine quartz particles (Min-USil 5). Exposure to $15-\mathrm{nm}$ SNPs generated oxidative stress in A549 cells as reflected by reduced glutathione (GSH) levels, elevated production of malondialdehyde (MDA) and lactate dehydrogenase (LDH) leakage, which is indicative of lipid peroxidation and membrane damage, respectively [102]. In the study by Wottrich et al. [103], A549 cells and macrophages (THP-1, Mono Mac 6) exposed to $60 \mathrm{~nm}$ amorphous SNPs showed distinctly higher mortality than did larger silica particles (diameter $100 \mathrm{~nm}$ ). Another study by Choi et al. [104], involving A549 cells and amorphous SNPs (14 nm), showed a pro-inflammatory response triggered by nanoparticles without blocking cell proliferation or causing cell death to any great extent. A recent work by Akhtar et al. [105] examined cytotoxicity (by MTT and LDH assay) and oxidative stress (ROS levels, membrane lipid peroxidation, GSH level and activity of GSH metabolizing enzymes) in A549 cells exposed for $48 \mathrm{~h}$ to amorphous SNPs of 10 and $80 \mathrm{~nm}$. The SNPs were cytotoxic to studied cells through oxidant generation (ROS and membrane lipid peroxidation) rather than depletion of GSH. Eom and Choi [106] studied oxidative stress caused by amorphous SNPs (7 and 5-15 nm) in human 
Table 2 In vitro studies on nanosilica particles (SNPs) toxicity

\begin{tabular}{|c|c|c|c|c|c|c|}
\hline Silica form & Size (primary) & Material characterization & Cells used & Test & $\begin{array}{l}\text { Biological endpoints and } \\
\text { findings }\end{array}$ & Ref \\
\hline Amorphous & $40 \mathrm{~nm}-5 \mu \mathrm{m}$ & Not specified & $\begin{array}{l}\text { A549 } \\
\text { HEp-2 } \\
\text { RPMI } 2650 \\
\text { RLE-6TN } \\
\text { N2a }\end{array}$ & $\begin{array}{l}\text { - Replication and } \\
\text { transcription assays } \\
\text { - Cell proliferation } \\
\text { and cell viability } \\
\text { assay } \\
\text { - Proteasome activity } \\
\text { assay } \\
\text { - } \\
\text { Immunofluorescence } \\
\text { and microscopy }\end{array}$ & $\begin{array}{l}\text { - Uptake of all particles into the } \\
\text { cytoplasm and nuclear } \\
\text { localization of nanoparticles } \\
\text { between } 40 \text { and } 70 \mathrm{~nm} \\
\text { - The uptake of NSPs in the } \\
\text { nucleus induced aberrant } \\
\text { clusters of topoisomerase I and } \\
\text { protein aggregates in the } \\
\text { nucleoplasm }\end{array}$ & [100] \\
\hline $\begin{array}{l}\text { Amorphous } \\
\text { (luminescent) }\end{array}$ & $50 \mathrm{~nm}$ & - Synthesis (ref. to literature) & $\begin{array}{l}\text { A549 } \\
\text { rat alveolar } \\
\text { macrophages }\end{array}$ & $\begin{array}{l}\text { - laser scanning } \\
\text { confocal microscope } \\
\text { - Comet Assay } \\
\text { - Pulse Field Gel } \\
\text { Electrophoresis } \\
\text { (PFGE) } \\
\text { - Western Blot } \\
\text { Analysis of DNA } \\
\text { Adducts/DNA } \\
\text { Agarose Gel } \\
\text { - DNA Repair Enzyme } \\
\text { Activity Assay } \\
\text { - Cell Proliferation } \\
\text { Assay } \\
\text { - Vybrant Apoptosis } \\
\text { Assay }\end{array}$ & $\begin{array}{l}\text { - Uptake not detected in the } \\
\text { nuclear region } \\
\text { - As compared to the A549 } \\
\text { cells, the nanoparticle } \\
\text { penetration rate was much } \\
\text { faster in the rat alveolar } \\
\text { macrophages } \\
\text { - No significant toxic effects } \\
\text { observed at the molecular and } \\
\text { cellular levels below a } \\
\text { concentration of } 0.1 \mathrm{mg} / \mathrm{ml}\end{array}$ & [101] \\
\hline $\begin{array}{l}\text { Amorphous } \\
\text { (colloidal) }\end{array}$ & 15 and $46 \mathrm{~nm}$ & $\begin{array}{l}\text { - Particle sizes and distribution } \\
\text { - Surface area (268 and } 52.5 \\
\mathrm{~m}^{2} / \mathrm{g} \text { for } 15 \text { and } 46 \mathrm{~nm} \\
\text { particle, respectively), } \\
\text { crystalline structure, major } \\
\text { trace metal impurities } \\
\text { - Hydrodynamic particle size in } \\
\text { water suspension }\end{array}$ & A549 & $\begin{array}{l}\text { - SRB } \\
\text { (sulforhodamine B) } \\
\text { and LDH assays } \\
\text { - Reduced } \\
\text { glutathione (GSH) } \\
\text { level } \\
\text { - DCFH assay (ROS } \\
\text { generation) } \\
\text { - Malondialdehyde } \\
\text { (MDA) assay }\end{array}$ & $\begin{array}{l}\text { - Cytotoxicity was dose- and } \\
\text { time-dependent } \\
\text { - Reduced glutathione (GSH) } \\
\text { levels and elevated MDA } \\
\text { production after exposure to } 15 \\
\text { nm SNPs }\end{array}$ & [102] \\
\hline Amorphous & $\begin{array}{l}60 \text { and } \\
100 \mathrm{~nm}\end{array}$ & $\begin{array}{l}\text { - Size distribution analysis } \\
\text { - Endotoxin concentration }\end{array}$ & $\begin{array}{l}\text { A549 } \\
\text { THP-1 } \\
\text { Mono Mac 6; } \\
\text { co-cultures }\end{array}$ & $\begin{array}{l}\text { - LDH assay } \\
\text { - Cytokine expression } \\
\text { (TNF- } \boldsymbol{\alpha}, \text { IL-6, IL-8) } \\
\text { - Light and } \\
\text { transmission electron } \\
\text { microscopy (TEM) }\end{array}$ & $\begin{array}{l}\text { - Cytotoxicity differed among } \\
\text { the cell lines and was dose- } \\
\text { and size-dependent (smaller } \\
\text { particles were more toxic) } \\
\text { - co-cultures showed an } \\
\text { increased sensitivity to particles } \\
\text { concerning the cytokine release } \\
\text { in comparison to the mono- } \\
\text { cultures of each cell type }\end{array}$ & [103] \\
\hline Amorphous & $\sim 14 \mathrm{~nm}$ & - Size distribution & $\begin{array}{l}\text { A549 } \\
\text { L-132 } \\
\text { HeLa } \\
\text { MNNG/ } \\
\text { HOS }\end{array}$ & $\begin{array}{l}\text { - MTT and WST-1 } \\
\text { assays } \\
\text { - Trypan blue } \\
\text { exclusion and LDH } \\
\text { assay } \\
\text { - Annexin V-PI assay } \\
\text { (fluorescence } \\
\text { microscopy) } \\
\text { - DCFH assay } \\
\text { - IL-8 expression } \\
\text { (ELISA) }\end{array}$ & $\begin{array}{l}\text { - Little cytotoxic effects in } 4 \text { cell } \\
\text { lines tested at the } \\
\text { concentration below } 250 \mu \mathrm{gg} / \mathrm{ml} \\
\text { within } 48 \mathrm{~h} \\
\text { - Exposing cancer cells to high } \\
\text { concentrations }(250-500 \mu \mathrm{g} / \mathrm{ml} \text { ) } \\
\text { for } 72 \mathrm{~h} \text { resulted in an } \\
\text { inflammatory response with } \\
\text { oxidative stress and membrane } \\
\text { damage, which varied with cell } \\
\text { type (A549>HOS }>\text { HeLa) } \\
\text { - SNPs triggered an } \\
\text { inflammation response without } \\
\text { causing considerable cell death } \\
\text { for both cancer cells and } \\
\text { normal cells }\end{array}$ & [104] \\
\hline
\end{tabular}


Table 2 In vitro studies on nanosilica particles (SNPs) toxicity (Continued)

\begin{tabular}{|c|c|c|c|c|c|c|}
\hline Amorphous & 10 and $80 \mathrm{~nm}$ & $\begin{array}{l}\text { o Provided by producer for the } \\
\text { primary particles (surface area: } \\
640 \text { and } 440 \mathrm{~m}^{2} / \mathrm{g} \text { for } 10 \text { and } \\
80 \mathrm{~nm} \text { particle, respectively) } \\
\text { o Hydrodynamic particle size } \\
\text { (in cell culture medium) }\end{array}$ & A549 & $\begin{array}{l}\text { - MTT and LDH } \\
\text { assays } \\
\text { - DCFH assay } \\
\text { - Intracellular } \\
\text { glutathione (GSH) } \\
\text { concentration } \\
\text { - Membrane lipid } \\
\text { peroxidation (LPO) } \\
\text { - Assay of glutathione } \\
\text { reductase and } \\
\text { glutathione } \\
\text { peoxidase }\end{array}$ & $\begin{array}{l}\text { - Cytotoxicity was dose- } \\
\text { dependent } \\
\text { - SNPs induced reactive oxygen } \\
\text { species and membrane lipid } \\
\text { peroxidation in dose-dependent } \\
\text { manner } \\
\text { - Both sizes of SNPs had little } \\
\text { effect on GSH level and the } \\
\text { activities of glutathione } \\
\text { metabolizing enzymes }\end{array}$ & {$[105]$} \\
\hline Amorphous & 7 and 5-15 nm & $\begin{array}{l}\text { o Surface area ( } 350 \text { and } 644 \\
\mathrm{~m}^{2} / \mathrm{g} \text { for } 7 \text { and } 5-15 \mathrm{~nm} \\
\text { particle, respectively) } \\
\text { o Size distribution (in the test } \\
\text { medium) }\end{array}$ & Beas-2B & $\begin{array}{l}\text { - Incorporation of } \\
\text { SNPs into the cells } \\
\text { (confocal LSM) } \\
\text { - MTT assay } \\
\text { - PI staining (flow } \\
\text { cytometry) } \\
\text { - Apoptosis } \\
\text { - DCFH assay } \\
\text { - Oxidative stress } \\
\text { responding } \\
\text { transcription factors } \\
\text { (Western blotting) }\end{array}$ & $\begin{array}{l}\text { - SNPS were incorporated into } \\
\text { the cells and distributed around } \\
\text { the nucleus area } \\
\text { - SNPs induced oxidative stress } \\
\text { via ROS formation and } \\
\text { induction of of antioxidant } \\
\text { enzymes (SOD and HO-1) } \\
\text { - Induction of Nrf-2-ERK MAP } \\
\text { kinase signaling pathway was } \\
\text { observed } \\
\text { - Overall, cells exposed to 5-15 } \\
\text { nm SNPs (porous) showed a } \\
\text { more sensitive response than } \\
\text { those exposed to } 7 \text { nm SNPS } \\
\text { (fumed) }\end{array}$ & {$[106]$} \\
\hline Amorphous & $10-20 \mathrm{~nm}$ & $\begin{array}{l}\text { o Provided by manufacturer } \\
\text { (surface area: } 140-180 \mathrm{~m}^{2} / \mathrm{g} \text { ) } \\
\text { o Primary particle size } \\
\text { o Endotoxin content (LPS) }\end{array}$ & A549 & $\begin{array}{l}\text { - MTT and LDH } \\
\text { assays } \\
\text { - DCFH assay } \\
\text { - SOD activity } \\
\text { determination } \\
\text { - Nitrate/nitrite } \\
\text { determination } \\
\text { - DNA oxidative } \\
\text { damage assay }\end{array}$ & $\begin{array}{l}\text { - Cytotoxicity was dose- and } \\
\text { time-dependent } \\
\text { - SNPs stimulated the ROS } \\
\text { generation, GSH depletion and } \\
\text { lower expression of SOD } \\
\text { activity in a dose-dependent } \\
\text { manner } \\
\text { - No NO production and } \\
\text { significant DNA oxidative } \\
\text { damage was observed after } \\
\text { treatment of cells with SNPS } \\
\text { - Co-treatment of LPS with } \\
\text { SNPs enhanced observed } \\
\text { cytoxicity and generation of } \\
\text { oxidative stress }\end{array}$ & [107] \\
\hline Amorphous & $\begin{array}{l}30,48,118 \text { and } \\
535 \mathrm{~nm}\end{array}$ & $\begin{array}{l}\text { - Synthesis method } \\
\text { - Hydrodynamic particle size } \\
\text { (in water and cell culture } \\
\text { medium) }\end{array}$ & HEL-30 & $\begin{array}{l}\text { - MTT and LDH } \\
\text { assays } \\
\text { - Reduced } \\
\text { glutathione (GSH) } \\
\text { and DCFH assay } \\
\text { - Transmission } \\
\text { electron microscopy } \\
\text { (TEM) }\end{array}$ & $\begin{array}{l}\text { - Cytotoxicity was dose- and } \\
\text { size-dependent (smaller } \\
\text { particles were more toxic) } \\
\text { - Uptake of all particles into the } \\
\text { cytoplasm (nuclear uptake not } \\
\text { studied) } \\
\text { - GSH level reduced significantly } \\
\text { of after exposure to } 30 \mathrm{~nm} \\
\text { nanoparticles } \\
\text { - No significant Reactive } \\
\text { Oxygen Species (ROS) } \\
\text { formation }\end{array}$ & [108] \\
\hline Amorphous & $\begin{array}{l}\text { 70, } 300 \text { and } 1000 \\
\mathrm{~nm}\end{array}$ & Not specified & XS52 & $\begin{array}{l}\text { - TEM analysis of cells } \\
\text { - LDH assay } \\
\text { - Proliferation }\left(\left[{ }^{3} \mathrm{H}\right]-\right. \\
\text { Thymidine } \\
\text { incorporation assay) }\end{array}$ & $\begin{array}{l}\text { - SNPs of } 300 \text { and } 1000 \mathrm{~nm} \\
\text { were incorporated into the cells } \\
\text { and located in cytoplasm only; } \\
\text { nanoparticles of } 70 \mathrm{~nm} \text { were } \\
\text { located in nucleus as well as } \\
\text { cytoplasm } \\
\text { - Cell proliferation was inhibited } \\
\text { by treatment with SNPs of all } \\
\text { sizes in dose-dependent } \\
\text { manner } \\
\text { - The growth of the cells was } \\
\text { more strongly inhibited by } \\
\text { smaller-sized SNPs }\end{array}$ & [109] \\
\hline
\end{tabular}


Table 2 In vitro studies on nanosilica particles (SNPs) toxicity (Continued)

\begin{tabular}{|c|c|c|c|c|c|c|}
\hline Amorphous & 15,30 and $365 \mathrm{~nm}$ & $\begin{array}{l}\text { - Size distribution } \\
\text { - Zeta potential } \\
\text { - Amorphous structure }\end{array}$ & $\mathrm{HaCaT}$ & $\begin{array}{l}\text { - CCK assay } \\
\text { - Cell cycle assay } \\
\text { - Annexin V-PI assay } \\
\text { (Flow cytometry) } \\
\text { - 2D-DIGE and, IEF } \\
\text { and SDS_PAGE } \\
\text { (protein expression) } \\
\text { - Western blot }\end{array}$ & $\begin{array}{l}\text { - Cytotoxicity was dose- and } \\
\text { size-dependent (smaller } \\
\text { particles were more toxic) } \\
\text { - Apoptosis was dose- and size- } \\
\text { dependent (smaller particles } \\
\text { induced higher apoptosis } \\
\text { frequency) } \\
\text { - Up-regulated proteins were } \\
\text { classified as oxidative stress- } \\
\text { associated proteins; } \\
\text { cytoskeleton-associated } \\
\text { proteins; molecular chaperones; } \\
\text { energy metabolism-associated } \\
\text { proteins; apoptosis and tumor- } \\
\text { associated proteins }\end{array}$ & {$[110]$} \\
\hline Amorphous & $15 \mathrm{~nm}$ & $\begin{array}{l}\text { - Size distribution } \\
\text { - Zeta potential } \\
\text { - Amorphous structure }\end{array}$ & $\mathrm{HaCaT}$ & $\begin{array}{l}\text { - Flow cytometric } \\
\text { analysis of } \\
\text { methylated DNA } \\
\text { - Real-time PCR } \\
\text { - Western blot }\end{array}$ & $\begin{array}{l}\text { - Treatment with SNPs induced } \\
\text { Global DNA hypomethylation }\end{array}$ & {$[111]$} \\
\hline Amorphous & 21 and $80 \mathrm{~nm}$ & $\begin{array}{l}\text { - Particle preparation and } \\
\text { dispersion } \\
\text { - Size, morphology and } \\
\text { chemical states of elements } \\
\text { - Hydrodynamic particle size } \\
\text { (dispersed in water) }\end{array}$ & $\begin{array}{l}\text { WS1 } \\
\text { CCD-966sk } \\
\text { MRC-5 } \\
\text { A549 } \\
\text { MKN-28 } \\
\text { HT-29 }\end{array}$ & $\begin{array}{l}\text { - MTT and LDH } \\
\text { assays }\end{array}$ & $\begin{array}{l}\text { - Toxicity was seen at } \\
\text { concentrations exceeding } 138 \\
\mu \mathrm{g} / \mathrm{ml} \\
\text { - Susceptibility to NSPs differed } \\
\text { among tested cell lines }\end{array}$ & [113] \\
\hline Amorphous & $20 \mathrm{~nm}$ & $\begin{array}{l}\text { Only provided by producer } \\
\text { (surface area: } 640 \pm 50 \mathrm{~m}^{2} / \mathrm{g} \text { ) }\end{array}$ & RAW264.7 & $\begin{array}{l}\text { - Membrane fluidity } \\
\text { measurements (FRAP } \\
\text { technique by LSCM) } \\
\text { - DCFH assay } \\
\text { - Intracellular free } \\
\text { calcium content }\end{array}$ & $\begin{array}{l}\text { - Exposure to SNPs increased } \\
\text { ROS generation and decrease } \\
\text { of the membrane fluidity } \\
\text { - Perturbation of Intracellular } \\
\text { free calcium homeostasis was } \\
\text { responsible for observed } \\
\text { cytotoxicity }\end{array}$ & [114] \\
\hline Amorphous & $14 \mathrm{~nm}$ & $\begin{array}{l}\text { Only provided by producer } \\
\text { (surface area: } 200 \mathrm{~m}^{2} / \mathrm{g} \text { ) }\end{array}$ & Caco-2 & $\begin{array}{l}\cdot \text { LDH and WST-1 } \\
\text { assay } \\
\text { - Fpg-modified } \\
\text { comet assay } \\
\text { - Total GSH content }\end{array}$ & $\begin{array}{l}\text { - Cytotoxicity observed } \\
\text { - Oxidative DNA damage } \\
\text { - Significant depletion of } \\
\text { intracellular GSH }\end{array}$ & [115] \\
\hline Amorphous & 21, 48 and $86 \mathrm{~nm}$ & $\begin{array}{l}\text { - Size distribution analysis } \\
\text { - Surface area ( } 225,106 \text { and } 39 \\
\mathrm{~m}^{2} / \mathrm{g} \text { for } 21,48 \text { and } 86 \mathrm{~nm} \\
\text { particle, respectively) } \\
\text { - structure }\end{array}$ & $\mathrm{L}-02$ & $\begin{array}{l}\text { - MTT and LDH } \\
\text { assays } \\
\text { - TEM assay } \\
\text { - DCFH, MDA and } \\
\text { GSH assay } \\
\text { - Annexin V-PI assay } \\
\text { (flow cytometry) } \\
\text { - DNA ladder assay } \\
\text { - Western blot }\end{array}$ & $\begin{array}{l}\text { - Cytotoxicity was dose- time - } \\
\text { and size-dependent (smaller } \\
\text { particles were more toxic) } \\
\text { - } 21 \mathrm{~nm} \text { SNPs induced ROS } \\
\text { generation, lipid peroxidation } \\
\text { and GSH depletion in a dose- } \\
\text { dependent manner } \\
\text { - } 21 \mathrm{~nm} \text { SNPs induced } \\
\text { apoptosis in a dose-dependent } \\
\text { manner }\end{array}$ & [116] \\
\hline Amorphous & $\begin{array}{l}\text { 4-40 } \mathrm{nm} \text { (mean } \\
\text { size: } 14)\end{array}$ & Not specified & HDMEC & $\begin{array}{l}\text { - MTS assay } \\
\text { - transmission } \\
\text { electron microscopy } \\
(\text { TEM) } \\
\text { - Ki67 expression and } \\
\text { IL-8 release }\end{array}$ & $\begin{array}{l}\text { - The particles were internalized } \\
\text { but they did not exert cytotoxic } \\
\text { effects } \\
\text { - Reduction of the proliferative } \\
\text { activity and a pro-inflammatory } \\
\text { stimulation were observed }\end{array}$ & [117] \\
\hline $\begin{array}{l}\text { Amorphous } \\
\text { (monodisperse) }\end{array}$ & $\begin{array}{l}14,15,16,19,60 \\
104,335 \mathrm{~nm}\end{array}$ & $\begin{array}{l}\text { - Particle preparation and } \\
\text { stability } \\
\text { - shape and size distribution } \\
\text { - surface area }(196,179,183, \\
145,33,28 \text { and } 7.7 \mathrm{~m}^{2} / \mathrm{g} \text { for } \\
14,15,16,19,60,104 \text { and } 335 \\
\text { nm particle, respectively) } \\
\text { - micropore volume } \\
\text { - Hydrodynamic particle size } \\
\text { (in water and cell culture } \\
\text { medium) }\end{array}$ & EAHY926 & $\begin{array}{l}\cdot \text { MTT and LDH } \\
\text { assays } \\
\text { - Annexin V-PI assay }\end{array}$ & $\begin{array}{l}\text { - Cytotoxicity was dose- and } \\
\text { size-dependent (smaller } \\
\text { particles were more toxic and } \\
\text { affected the exposed cells } \\
\text { faster) } \\
\text { - Cell death predominantly } \\
\text { caused by necrosis }\end{array}$ & [118] \\
\hline
\end{tabular}


Table 2 In vitro studies on nanosilica particles (SNPs) toxicity (Continued)

\begin{tabular}{|c|c|c|c|c|c|c|}
\hline Amorphous & 21 and $48 \mathrm{~nm}$ & $\begin{array}{l}\text { - Size distribution analysis } \\
\text { - Surface area ( } 225 \text { and } 106 \\
\mathrm{~m}^{2} / \mathrm{g} \text { for } 21 \text { and } 48 \mathrm{~nm} \\
\text { particle, respectively) } \\
\text { - structure }\end{array}$ & $\mathrm{H} 9 \mathrm{c} 2(2-1)$ & $\begin{array}{l}\text { - MTT and LDH } \\
\text { assays } \\
\text { • Hematoxylin and } \\
\text { eosin staining } \\
\text { - DCFH, intracellular } \\
\text { MDA and GSH assays } \\
\text { - Flow cytometry (cell } \\
\text { cycle) } \\
\text { - Western blot }\end{array}$ & $\begin{array}{l}\text { - Cytotoxicity was dose- time - } \\
\text { and size-dependent (smaller } \\
\text { particles were more toxic) } \\
\text { - ROS generation in a dose- } \\
\text { dependent manner; increased } \\
\text { level of MDA and decreased } \\
\text { concentration of GSH indicated } \\
\text { oxidative stress } \\
\text { - Cell cycle arrest in G1 phase } \\
\text { - Dose-dependent expression of } \\
\text { p53 and p21 for } 21 \text { nm SNP }\end{array}$ & [119] \\
\hline Amorphous & $\begin{array}{l}\text { From } 20 \mathrm{~nm} \text { to } \\
\text { below } 400 \mathrm{~nm}\end{array}$ & $\begin{array}{l}\text { - the dispersion characteristics } \\
\text { (size, size distribution, size } \\
\text { evolution) } \\
\text { - zeta potential }\end{array}$ & 3T3-L1 & - comet assay & $\begin{array}{l}\text { - No detectable genotoxicity } \\
\text { (the results were independently } \\
\text { validated in two separate } \\
\text { laboratories) }\end{array}$ & [120] \\
\hline $\begin{array}{l}\text { Amorphous } \\
\text { (monodisperse) }\end{array}$ & 16, 60 and $104 \mathrm{~nm}$ & $\begin{array}{l}\text { - Particle preparation and } \\
\text { stability } \\
\text { - shape and size distribution } \\
\text { - surface area (183, } 33 \text { and } 28 \\
\mathrm{~m}^{2} / \mathrm{g} \text { for } 16,60 \text { and } 104 \mathrm{~nm} \\
\text { particle, respectively) } \\
\text { - micropore volume } \\
\text { - Hydrodynamic particle size } \\
\text { (in water and cell culture } \\
\text { medium) }\end{array}$ & A549 & $\begin{array}{l}\text { - MTT assay } \\
\text { - cytochalasin-B } \\
\text { micronucleus assay } \\
\text { (CBMN) alone or in } \\
\text { combination with } \\
\text { FISH-centromeric } \\
\text { staining } \\
\text { - Alkaline Comet } \\
\text { assay } \\
\text { - Measurements of } \\
\text { cell-associated silica } \\
\text { (ICP-MS) }\end{array}$ & $\begin{array}{l}\text { - Results suggest that non- } \\
\text { cytotoxic doses of SNPs may be } \\
\text { capable of inducing slight } \\
\text { chromosome breakage, loss } \\
\text { and mitotic slippage, and at } \\
\text { higher concentration possibly } \\
\text { mitotic arrest. }\end{array}$ & [122] \\
\hline $\begin{array}{l}\text { Amorphous } \\
\text { (monodisperse) }\end{array}$ & $\begin{array}{l}\text { from } 2 \text { up to } 335 \\
\mathrm{~nm}\end{array}$ & $\begin{array}{l}\text { - Particle preparation and } \\
\text { stability } \\
\text { - shape and size distribution } \\
\text { - surface area (from } 232 \text { to } 7.7 \\
\mathrm{~m}^{2} / \mathrm{g} \text { ) } \\
\text { - micropore volume } \\
\text { - Hydrodynamic particle size } \\
\text { (in water and cell culture } \\
\text { medium) } \\
\text { - Zeta potential }\end{array}$ & $\begin{array}{l}\text { J774 } \\
\text { EAHY926 } \\
\text { 3T3 } \\
\text { Human } \\
\text { erythrocytes }\end{array}$ & $\begin{array}{l}\text { - MTT and WST-1 } \\
\text { assays } \\
\text { - RBC hemolysis }\end{array}$ & $\begin{array}{l}\text { - in murine macrophages, the } \\
\text { cytotoxic response, after } \\
\text { treatment with SNPs of } 17 \\
\text { different sizes, increased with } \\
\text { external surface area and } \\
\text { decreased with micopore } \\
\text { volume } \\
\text { - in human endothelial cells } \\
\text { and mouse embryo fibroblast } \\
\text { the cytotoxicity increased with } \\
\text { surface roughness and decrease } \\
\text { in diameter } \\
\text { - the hemolytic activity of SNPs } \\
\text { in human erythrocytes } \\
\text { increased with the diameter of } \\
\text { SNPs }\end{array}$ & {$[141]$} \\
\hline Amorphous & $30 \mathrm{~nm}$ & $\begin{array}{l}\text { - Provided by producer for } \\
\text { primary partilcles (surface area: } \\
165 \mathrm{~m}^{2} / \mathrm{g} \text { ) } \\
\text { - Hydrodynamic particle size } \\
\text { (in PBS and cell culture } \\
\text { medium) } \\
\text { - Adsorption of proteins from } \\
\text { the test media in the absence } \\
\text { of cells }\end{array}$ & $\begin{array}{l}3 \mathrm{T3} \\
\text { hT } \\
\text { RAW264.7 }\end{array}$ & $\begin{array}{l}\text { - MTS assay } \\
\text { - Uptake (flow } \\
\text { cytometry) } \\
\text { - DCFH assay } \\
\text { - Lysosomal } \\
\text { membrane integrity } \\
\text { - Mitochodrial } \\
\text { membrane potential } \\
\text { - Apoptosis (caspase- } \\
\text { 3, and caspase-7 } \\
\text { activation; Annexin V- } \\
\text { PI assay) }\end{array}$ & $\begin{array}{l}\text { - SNPs depleted serum proteins } \\
\text { from cell culture media } \\
\text { - SNPs cytotoxicity was dose-, } \\
\text { time- and cell line dependent- } \\
\text { dependent } \\
\text { - SNPs induced significant ROS } \\
\text { generation in all cell lines } \\
\text { - No detectable destabilization } \\
\text { of lysosomal membranes was } \\
\text { observed } \\
\text { - Incubation with SNPs } \\
\text { decreased mitochodrial } \\
\text { membrane potential in hT and } \\
\text { RAW cells } \\
\text { - SNPs triggered different extent } \\
\text { of cell apoptosis depending on } \\
\text { the cell line tested }\end{array}$ & [140] \\
\hline $\begin{array}{l}\text { Amorphous } \\
\text { (mesoporous) }\end{array}$ & $\begin{array}{l}110 \mathrm{~nm} \text { (pore } \\
\text { diameter of } \sim 2.5 \\
\mathrm{~nm} \text { ) }\end{array}$ & $\begin{array}{l}\text { - Structure } \\
\text { - surface area }\left(910 \mathrm{~m}^{2} / \mathrm{g}\right) \\
\text { - pore volume } \\
\text { - stability in aqueous solution }\end{array}$ & $\begin{array}{l}\text { 3T3-L1 } \\
\text { MCF-7 } \\
\text { K562 }\end{array}$ & $\begin{array}{l}\text { - Confocal } \\
\text { microscope } \\
\text { - TEM } \\
\text { - Flow cytometry }\end{array}$ & $\begin{array}{l}\text { - Particles were internalized into } \\
\text { cells and accumulated in } \\
\text { cytoplasm } \\
\text { - No apparent cytotoxicity }\end{array}$ & {$[123]$} \\
\hline
\end{tabular}


Table 2 In vitro studies on nanosilica particles (SNPs) toxicity (Continued)

\begin{tabular}{|c|c|c|c|}
\hline $\begin{array}{l}\text { Amorphous } \\
\text { (mesoporous) }\end{array}$ & $\begin{array}{l}\text { Not specified } \\
\text { (MCM-41 particle } \\
\text { type) }\end{array}$ & $\begin{array}{l}\text { - Synthesis and } \\
\text { functionalization of particles } \\
\text { - Zeta potential } \\
\text { - Cylindrical pores with a } \\
\text { diameter around } 5 \mathrm{~nm}\end{array}$ & HeLa \\
\hline $\begin{array}{l}\text { Amorphous } \\
\text { (mesoporous) }\end{array}$ & $\begin{array}{l}108,110,111 \text { and } \\
115 \mathrm{~nm}\end{array}$ & $\begin{array}{l}\text { - Synthesis (ref to the previous } \\
\text { study) and surface } \\
\text { modification } \\
\text { - Zeta potential } \\
\text { - Surface area (780,980, } 930 \\
\text { and } 1050 \mathrm{~m}^{2} / \mathrm{g} \text { for } 108,110 \text {, } \\
111 \text { and } 115 \mathrm{~nm} \text { particle, } \\
\text { respectively) } \\
\text { - pore volume and pore size } \\
\text { distribution (2.6-2.0 } \mathrm{nm} \text { ) }\end{array}$ & $\begin{array}{l}\text { hMSCs } \\
\text { 3T3-L1 }\end{array}$ \\
\hline
\end{tabular}

- MTT, WST-1 and

LDH assays

- Flow cytometry for

$\mathrm{Pl}$

- TEM observations

- MTT assay

- Flow cytometry for

the uptake

- Cellular

differentiation and

cytochemical assay
- No cytotoxicity was observed [126]

up to $50 \mu \mathrm{g} / \mathrm{ml}$

- Particles interfered with MTT assay

- The modulation of surface charge and its threshold affects the uptake and is specific to cell type

- Positive correlation of positive surface charge and the uptake by the cells

- Uptake was through clathrin and actin-dependent endocytosis

- Uptake did not affect cells viability, proliferation and differentiation

\begin{tabular}{|c|c|c|c|}
\hline $\begin{array}{l}\text { Amorphous } \\
\text { (mesoporous } \\
\text { silica nanorods }\end{array}$ & $\begin{array}{l}200 \times 80 \mathrm{~nm} \text { (pore } \\
\text { diameter of } \sim 3 \\
\mathrm{~nm} \text { ) }\end{array}$ & $\begin{array}{l}\text { - Preparation and } \\
\text { functionalization }\end{array}$ & HeLa \\
\hline
\end{tabular}

microscopy
- Particles were endocytosed by [127] the cells and biocompatible (concentration used: $0.2 \mathrm{mg}$ / $\mathrm{mL})$

iron oxide NPs)

\begin{tabular}{|c|c|c|c|c|}
\hline $\begin{array}{l}\text { Amorphous } \\
\text { (mesoporous) }\end{array}$ & $\begin{array}{l}30,50,110,170 \\
\text { and } 280 \mathrm{~nm}\end{array}$ & $\begin{array}{l}\text { - Synthesis, suspension stability } \\
\text { (no interparticle aggregation), } \\
\text { hydrodynamic diamaters, zeta } \\
\text { potential }\end{array}$ & HeLa & $\begin{array}{l}\cdot \text { MTT } \\
\cdot \text { onfocal laser } \\
\text { scanning microscopy } \\
\cdot \text { ICP-MS }\end{array}$ \\
\hline
\end{tabular}

Amorphous $\quad<130 \mathrm{~nm}$ (pore

(mesoporous) diameter of $\sim 2$

loaded with $\mathrm{nm}$ ) anticancer

drugs)

Amorphous (mesoporous)

\section{$150 \mathrm{~nm}$ (pore}

\section{diameter of $\sim 2 \quad$ aggregation/stability in} aqueous solution diameter of $\sim 2.4$ $\mathrm{nm})$
- Synthesis, functionalization, surface area $\left(850 \mathrm{~m}^{2} / \mathrm{g}\right)$, zeta potential

$\begin{array}{ll}\text { PANC-1 } & \cdot \text { Fluorescence and } \\ \text { AsPC-1 } & \text { confocal microscopy } \\ \text { Capan-1 } & \end{array}$

MKN45

SW480

HeLa - Flow cytometry

- Fluorescence

microscopy

- Cellular uptake is highly particle size-dependent (with the optimum size of $50 \mathrm{~nm}$ ); little cytotoxicity up to $100 \mathrm{mg} /$ $\mathrm{ml}$

- The particles offer the possibility of controlled release of anticancer drugs (non-loaded particles did not caused cytotoxicity)

- Uptake of particles can be regulated by different surface functionalization

- More negatively charged particles were able to escape from endosomes

\begin{tabular}{|c|c|c|c|c|}
\hline $\begin{array}{l}\text { norp } \\
\text { nesop }\end{array}$ & $\begin{array}{l}100-300 \mathrm{~nm} \text { (pore } \\
\text { diameter of } \sim 3 \\
\mathrm{~nm} \text { ) - }\end{array}$ & $\begin{array}{l}\text { - Synthesis (ref. to the previous } \\
\text { study), funcionalization, surface } \\
\text { area }\left(1138 \mathrm{~m}^{2} / \mathrm{g}\right) \text {, pore }\end{array}$ & $\mathrm{R}$ & $\begin{array}{l}\text { - Hemolysis assay } \\
\text { - UVNis spectroscopy } \\
\text { - Flow cytometry }\end{array}$ \\
\hline
\end{tabular}
available amorphous silica material volumes, number of silano - The hemolytic activity of silica nanoparticles depends only on the concentration of negatively charged silanol groups - Mesoporous particles exhibit a high compatibility towards RBCs as most of the silanols are located in the interior of the particles that are not accessible by the RBCs membranes

\begin{tabular}{|c|c|c|c|c|}
\hline $\begin{array}{l}\text { Amorphous } \\
\text { (mesoporous) }\end{array}$ & $\begin{array}{l}\text { 300-650 nm (pore } \\
\text { diameter of } 31 \AA \text { ) } \\
\text { and SBA-15 type } \\
\text { (>hundreds of nm, } \\
\text { pore diameter of }\end{array}$ & $\begin{array}{l}\text { - Synthesis, } \\
\text { - Order of mesostructures, } \\
\text { surface area ( } 821 \text { and } 506 \mathrm{~m}^{2} \text { / } \\
\text { g), wall thickness, composition }\end{array}$ & $\begin{array}{l}\text { HL-60 } \\
\text { Jurkat }\end{array}$ & $\begin{array}{l}\text { - Oxygen } \\
\text { consumption assay } \\
\text { - ATP formation assay } \\
\text { - Cellular GSH assay }\end{array}$ \\
\hline
\end{tabular}
- Particles with larger size and larger pores caused

concentration- and time dependent inhibition of cellular respiration

- Both nanoparticles were toxic to the isolated mitochondria - No significant changes in cellular glutathione level was observed 
Table 2 In vitro studies on nanosilica particles (SNPs) toxicity (Continued)

\begin{tabular}{|c|c|c|c|}
\hline $\begin{array}{l}\text { Amorphous } \\
\text { (mesoporous } \\
\text { and silica } \\
\text { nanospheres) }\end{array}$ & $\begin{array}{l}250 \mathrm{~nm} ; 166 \times 320 \\
\mathrm{~nm} \text { (pore diameter } \\
=3.5 \mathrm{~nm} \text { ) }\end{array}$ & $\begin{array}{l}\text { - Synthesis and } \\
\text { functionalization } \\
\text { - Number of particles per } \\
\text { gram, surface area ( } 4.1 \text { and } 0.2 \\
\mathrm{~m}^{2} / \text { particle for mesoporous } \\
\text { and spherical particle, } \\
\text { respectively) }\end{array}$ & SK-N-SH \\
\hline
\end{tabular}

- Staining with trypan - The cytotoxicity of particles was related to the adsorptive determination of surface area of the particle (the viable cells using a most toxic malodorous silica hemacytometer are those with the largest BET surface areas) - Dependency of cytotoxicity on the nature of the attached functional groups cannot be ruled out

\begin{tabular}{|c|c|c|c|c|c|c|}
\hline $\begin{array}{l}\text { Amorphous } \\
\text { (mesoporous) }\end{array}$ & $\begin{array}{l}270 \pm 50 \mathrm{~nm} \text { (pore } \\
\text { diameter of } 3.9 \\
\mathrm{~nm} \text { ) and } 2.5 \mu \mathrm{m} \pm \\
500 \mathrm{~nm} \text { (pore } \\
\text { diameter of } 2.8 \\
\mathrm{~nm} \text { ) }\end{array}$ & $\begin{array}{l}\text { - Synthesis } \\
\text { - The structural and textural } \\
\text { characterizations } \\
\text { - Surface area(520 and } 547 \mathrm{~m}^{2} \text { / } \\
\text { g for } 270 \mathrm{~nm} \text { and } 2.5 \mu \mathrm{m} \\
\text { particle, respectively) } \\
\text { - LPS concentration analysis }\end{array}$ & $\begin{array}{l}\text { Human } \\
\text { monocyte- } \\
\text { derived } \\
\text { dendritic } \\
\text { cells }\end{array}$ & $\begin{array}{l}\text { - Apoptosis/necrosis } \\
\text { (Annexin V/PI assay) } \\
\text { - production of } \\
\text { cytokinesIL-10 and IL- } \\
12 \text { p70,IL-12, IL-10 } \\
\text { - confocal } \\
\text { microscopy, TEM }\end{array}$ & $\begin{array}{l}\text { - Viability, uptake and immune } \\
\text { regulatory markers were } \\
\text { affected with increasing size } \\
\text { and dose }\end{array}$ & {$[134]$} \\
\hline $\begin{array}{l}\text { Amorphous } \\
\text { (mesoporous) }\end{array}$ & $\begin{array}{l}\text { 190, } 420 \text { and } 1220 \\
n m\end{array}$ & $\begin{array}{l}\text { - Synthesis and } \\
\text { functionalization } \\
\text { - Size distribution } \\
\text { - Dispersity and porosity } \\
\text { - Surface area (220-650 m²/g) } \\
\text { - Zeta potential }\end{array}$ & $\begin{array}{l}\text { MDA-MB-468 } \\
\text { COS-7 }\end{array}$ & $\begin{array}{l}\text { - MTT assay } \\
\text { - The biodegradation } \\
\text { experiments } \\
\text { - Intracellular } \\
\text { localization of } \\
\text { particles }\end{array}$ & $\begin{array}{l}\text { - The cytotoxicity of particles } \\
\text { was highly correlated with } \\
\text { particle sizes ((smaller particles } \\
\text { were more toxic) } \\
\text { - The biodegradation products } \\
\text { of spherical E-MS particles } \\
\text { showed no toxicity } \\
\text { - The residual surfactant bound } \\
\text { to the particles has a much } \\
\text { smaller contribution to the } \\
\text { cytotoxicity than the free one } \\
\text { - The smaller particles were } \\
\text { more easily endocytosed and } \\
\text { consequently located within } \\
\text { lysosomes }\end{array}$ & {$[135]$} \\
\hline Amorphous & 100 and $200 \mathrm{~nm}$ & $\begin{array}{l}\text { - rod-shaped and spherical } \\
\text { particles (Stöber), not-coated } \\
\text { and coated with fibronectin or } \\
\text { polyethylene glycol (PEG), } \\
\text { - Primary and aggregate size, } \\
\text { surface area ( } 9.2 \text { and } 4.6 \mathrm{~m}^{2} / \mathrm{g} \\
\text { for silica rods and } 27.3 \text { and } \\
14.2 \mathrm{~m}^{2} / \mathrm{g} \text { for silica spheres), } \\
\text { crystallinity, impurities, zeta } \\
\text { potential }\end{array}$ & MET-5A & $\begin{array}{l}\text { - LDH assay } \\
\text { - Expression of IL-8 } \\
\text { - Simulated stretch } \\
\text { imposed on the cells }\end{array}$ & $\begin{array}{l}\text { - Dosimetric comparison of } \\
\text { acicular and isotropic } \\
\text { particulate materials is not } \\
\text { straightforward } \\
\text { - In the absence of simulated } \\
\text { lung function (stretch), cells } \\
\text { showed no significant } \\
\text { enhancement of cytotoxicity or } \\
\text { inflammation release } \\
\text { - PEG surface treatment tended } \\
\text { to reduce the cytotoxicity and } \\
\text { IL-8 release from particle } \\
\text { exposures suggesting the } \\
\text { significance of adhesive } \\
\text { interactions e.g. for membrane } \\
\text { binding/signal transduction }\end{array}$ & [136] \\
\hline Amorphous & $\begin{array}{l}130 \mathrm{~nm} \text { and } 155 \\
\mathrm{~nm} \text {; iron oxide } \\
\text { particle with silica } \\
\text { shell }(80 \mathrm{~nm})\end{array}$ & $\begin{array}{l}\text { - Size distribution } \\
\text { - Reference given for the } \\
\text { description in detail }\end{array}$ & $\begin{array}{l}\text { Hmy2 } \\
\text { Jurkat } \\
\text { U937 } \\
\text { PC3; } \\
\text { human } \\
\text { peripheral } \\
\text { blood cells }\end{array}$ & $\begin{array}{l}\text { - MTT assay and } \\
\text { Trypan Blue exclusion } \\
\text { - Scanning electron } \\
\text { microscopy } \\
\text { - DCFH assay }\end{array}$ & $\begin{array}{l}\text { - The cytotoxicity of particles } \\
\text { depended on the cell type } \\
\text { tested } \\
\text { - No direct correlation between } \\
\text { ROS production and cell } \\
\text { toxicity. } \\
\text { - PEG-ylation of SNP protected } \\
\text { the particles from protein } \\
\text { adsorption on the external } \\
\text { surface of the NPs and } \\
\text { consequently no agglomeration } \\
\text { in culture medium was } \\
\text { observed. } \\
\text { - The availability of the particles } \\
\text { to be internalized by the cells } \\
\text { depended on the size and } \\
\text { morphology of the aggregates. }\end{array}$ & [137] \\
\hline
\end{tabular}


Table 2 In vitro studies on nanosilica particles (SNPs) toxicity (Continued)

\begin{tabular}{|c|c|c|c|c|c|c|}
\hline Crystalline & $\begin{array}{l}\text { Particle sizes not } \\
\text { uniform }(7.21,9.08 \\
\text { and } 123.21 \mathrm{~nm})\end{array}$ & - Size and concentration & WIL2-NS & $\begin{array}{l}\text { - MTT assay } \\
\text { - Population Growth } \\
\text { Assay } \\
\text { - Apoptosis Assay by } \\
\text { Flow Cytometry } \\
\text { - Cytokinesis Block } \\
\text { Micronucleus Assay } \\
\text { - Comet Assay } \\
\text { - HPRT Mutation } \\
\text { Assay }\end{array}$ & $\begin{array}{l}\text { - Significant dose-dependent } \\
\text { decrease in viability } \\
\text { - with increasing dose of } \\
\text { particles } \\
\text { - Fourfold increase in } \\
\text { micronucleated binucleated } \\
\text { cells frequency was detected, } \\
\text { while no significant difference } \\
\text { was measured by the Comet } \\
\text { assay }\end{array}$ & [99] \\
\hline
\end{tabular}

bronchial epithelial cells (BEAS-2B) and observed the formation of ROS and induction of antioxidant enzymes.

Shi et al. [107] exposed A549 cells to amorphous SNPs $(10-20 \mathrm{~nm})$ at concentrations up to $200 \mu \mathrm{g} / \mathrm{ml}$ and observed low cytotoxicity as measured by MTT and LDH assays. However, co-treatment with the same nanoparticles and lipopolysaccharide, a bacterial product that may contaminate (nano)materials, significantly enhanced the cytotoxicity.

$\mathrm{Yu}$ et al. [108] examined the cytotoxic activity (by MTT and LDH assay) of well-dispersed amorphous silica particles (30-535 nm) in mouse keratinocytes. All sizes of particles were taken up into the cell cytoplasm; nuclear uptake was not studied. The toxicity was dose and size dependent, with 30- and 48-nm particles being more cytotoxic than 118 - and $535-\mathrm{nm}$ particles. The reduced GSH level significantly decreased only after exposure to 30-nm nanoparticles [108]. Nabeshi et al. [109] showed the size-dependent cytotoxic effects of amorphous silica particles (70, 300 and $1000 \mathrm{~nm}$ ) on mouse epidermal Langerhans cells. The smallest particles induced greater cytotoxicity (by LDH assay) and inhibited cellular proliferation (by $\left[{ }^{3} \mathrm{H}\right]$-thymidine incorporation). The observed effects were associated with the quantity of particle uptake into the cells.

Yang et al. [110] evaluated the effects of amorphous SNPs (15 and $30 \mathrm{~nm}$ ) and micron-sized silica particles on cellular viability, cell cycle, apoptosis and protein expression in the human epidermal keratinocyte cell line HaCaT. Microscopy examination revealed morphological changes after 24-h exposure; cell growth also appeared to be significantly inhibited. The cellular viability of $\mathrm{HaCaT}$ cells was significantly decreased, and the amount of apoptotic cells was increased in a dose-dependent manner after treatment with nano- and micron-sized $\mathrm{SiO}_{2}$ particles. Furthermore, smaller silica particles were more cytotoxic and induced a higher apoptotic rate. Proteomic analysis revealed differential induction of expression of 16 proteins by $\mathrm{SiO}_{2}$ exposure; proteins were classified into 5 categories according to their functions: oxidative stress-associated proteins, cytoskeletonassociated proteins, molecular chaperones, energy metabolism-associated proteins, and apoptosis and tumor- associated proteins. The expression levels of the differentially expressed proteins were associated with particle size [110]. In a recently published study [111], the same research group used these SNPs to study the global DNA methylation profiles in $\mathrm{HaCaT}$ cells; the authors reported that nanosilica treatment can induce epigenetic changes.

Cousins et al. [112] exposed murine fibroblasts to small amorphous (colloidal) silica particles (7, 14 and $21 \mathrm{~nm}$ ) over a long incubation period (1, 3 and 7 days and up to 7 weeks) and observed a distinctive cellular response affecting the morphologic features, adhesion and proliferation of the fibroblasts but not cell viability. Chang et al. [113] exposed selected human fibroblast and cancer cell lines for $48 \mathrm{~h}$ to amorphous SNPs and assessed cellular viability by MTT and LDH assays. Cytotoxicity was seen at concentrations $>138 \mu \mathrm{g} / \mathrm{ml}$ and depended on the metabolic activity of the cell line. However, the average primary size of tested silica particles was 21 and $80 \mathrm{~nm}$, but their average hydrodynamic particle size was 188 and $236 \mathrm{~nm}$, respectively, so in media, aggregates/agglomerates were formed.

In the study of Yang et al. [114], cell membrane injury induced by 20 -nm amorphous silica nanoparticles in mouse macrophages was closely associated with increased intracellular oxidative stress, decreased membrane fluidity, and perturbation of intracellular calcium homeostasis.

Besides inhalation, ingestion is considered a major uptake route of nanoparticles into the human body [3]; however, the possible harmful effects of engineered nanoparticles in the gastrointestinal tract are still largely unknown. Recently, Gerloff et al. [115] investigated the cytotoxic and DNA damaging properties of amorphous fumed $\mathrm{SiO}_{2}$ nanoparticles $(14 \mathrm{~nm})$ in the human colon epithelial cell-line Caco-2. Exposure to SNPs for up to $24 \mathrm{~h}$ caused cell mortality, significant DNA damage and total glutathione depletion. The results of an in vivo study of mice fed nanosized silica are discussed in section 3.2.2.

Ye et al. [116] reported on induced apoptosis in a human hepatic cell line after exposure to amorphous (colloidal) SNPs (21, 48 and $86 \mathrm{~nm}$ ). The viability of 
Table 3 In vivo studies on nanosilica particles (SNPs) toxicity

\begin{tabular}{|c|c|c|c|c|c|c|}
\hline $\begin{array}{l}\text { Silica } \\
\text { form }\end{array}$ & $\begin{array}{l}\text { Size } \\
\text { (primary) }\end{array}$ & $\begin{array}{l}\text { Material } \\
\text { characterization }\end{array}$ & Exposure model & Test & $\begin{array}{l}\text { Biological endpoints and } \\
\text { findings }\end{array}$ & Ref \\
\hline Quartz & $\begin{array}{l}\text { 10-20 } \mathrm{nm} \\
\text { (average size: } \\
\text { 12), 30-65 } \\
\text { (average size: } \\
50), 300 \mathrm{~nm} \text { - } \\
2 \mu \mathrm{m}\end{array}$ & $\begin{array}{l}\text { - Synthesis } \\
\text { - Surface area } \\
\text { - Crystallinity } \\
\text { - Metal } \\
\text { impurities }\end{array}$ & $\begin{array}{l}\text { Rats instilled intratracheally } \\
\text { with various particle types } \\
(1 \mathrm{or} 5 \mathrm{mg} / \mathrm{kg}) \text {, sacrificed at } \\
24 \mathrm{~h}, 1 \text { week, } 1 \text { month, } \\
\text { and } 3 \text { months post- } \\
\text { exposure }\end{array}$ & $\begin{array}{l}\text { - Bronchoalveolar lavage (BAL) } \\
\text { fluid analysis: cell counts, } \\
\text { differentials, and pulmonary } \\
\text { biomarkers (Lactate } \\
\text { dehydrogenase (LDH), alkaline } \\
\text { phosphatase (ALP), and } \\
\text { lavage fluid protein) } \\
\text { - Cell proliferation } \\
\text { - Morphological/ } \\
\text { Histopathology examination } \\
\text { - Hemolytic Potential of } \\
\text { particles }\end{array}$ & $\begin{array}{l}\text { Exposures to the various } \\
\text { quartz particles produced } \\
\text { differential degrees of } \\
\text { pulmonary inflammation and } \\
\text { cytotoxicity, which were not } \\
\text { consistent with particle size } \\
\text { but correlated with surface } \\
\text { activity, particularly hemolytic } \\
\text { potential. }\end{array}$ & [148] \\
\hline Silica dust & $\begin{array}{l}10 \pm 5 \mathrm{~nm} ; \\
\text { and } 0.5-10 \\
\mu \mathrm{m}(80 \% \text { of } \\
\text { the particles } \\
1-5 \mu \mathrm{m})\end{array}$ & $\begin{array}{l}\text { - Composition } \\
\text { uknown } \\
\text { - Surface area }\end{array}$ & $\begin{array}{l}\text { Rats instilled intratracheally } \\
(20 \mathrm{mg}) \text {, sacrificed } 1 \text { and } 2 \\
\text { months after dosing }\end{array}$ & $\begin{array}{l}\text { - The changes of lung/body } \\
\text { coefficient and } \\
\text { hydroxyproline content } \\
\text { - Pathologic examination } \\
\text { - Immunohistochemical } \\
\text { staining for IL-4 and TGF- } \\
\text { beta1 }\end{array}$ & $\begin{array}{l}\text { One month after instillation } \\
\text { cellular nodules (Stage I } \\
\text { silicosis) were found in the } \\
\text { nanosized } \mathrm{SiO}_{2} \text { group, while } \\
\text { in microsized } \mathrm{SiO}_{2} \text { group } \\
\text { Stage II, II+ of silicotic } \\
\text { nodules were observed. } \\
\text { Two months after instillation, } \\
\text { still only Stage I silicotic } \\
\text { nodules in nanosilica group } \\
\text { were found, while in the } \\
\text { micro-silica group the disease } \\
\text { progressed and Stage II, and } \\
\text { III silicotic nodules were } \\
\text { found. } \\
\text { The experiment revealed that } \\
\text { in rats the effect of } \\
\text { fibrogenesis of nano-SiO } \\
\text { might be milder than that of } \\
\text { micro-SiO } \\
\text {. }\end{array}$ & {$[147]$} \\
\hline $\begin{array}{l}\text { Ludox } \\
\text { colloidal silica }\end{array}$ & - & $\begin{array}{l}\text { - Mass median } \\
\text { aerodynamic } \\
\text { diameter }(2.9,3.3 \\
\text { and } 3.7 \mu \mathrm{m}) \\
\text { - Chamber } \\
\text { Ludox } \\
\text { concentration }\end{array}$ & $\begin{array}{l}\text { Rats Inhalation (nose-only) } \\
\text { for } 2 \text { or } 4 \text { weeks at } \\
\text { concentrations } 10,50 \text { and } \\
150 \mathrm{mg} / \mathrm{m}^{3} \text {. } \\
\text { Additional groups of rats } \\
\text { exposed for } 4 \text { weeks were } \\
\text { given a 3-month recovery } \\
\text { period }\end{array}$ & $\begin{array}{l}\text { - Lung silica analysis } \\
\text { - BAL analysis: cell differential } \\
\text { counts and biochemical assay } \\
\text { (LDH, ALP, lavage fluid } \\
\text { protein) } \\
\text { - Pulmonary macrophage cell } \\
\text { culture and phagocytosis } \\
\text { assay } \\
\text { - SEM ananlysis } \\
\text { - Additional groups of animals } \\
\text { were processed for cell } \\
\text { labeling studies or lung } \\
\text { deposition studies. }\end{array}$ & $\begin{array}{l}\text { The inflammatory responses, } \\
\text { mainly seen as increased } \\
\text { numbers of neutrophils in } \\
\text { BALF, following the } 2 \text { and/or } \\
4 \text { weeks of exposure was } \\
\text { evident at } 50 \mathrm{mg} / \mathrm{m}^{3} \text { (or } \\
\text { higher) group. Three months } \\
\text { after exposure most } \\
\text { biochemical parameters } \\
\text { returned to control values. } \\
\text { Results showed that } \\
\text { exposures to } 150 \mathrm{mg} / \mathrm{m} 3 \\
\text { Ludox for } 2 \text { or } 4 \text { weeks } \\
\text { produced pulmonary } \\
\text { inflammation along with } \\
\text { increases in BAL protein, LDH, } \\
\text { and alkaline phosphatase } \\
\text { values (p less than 0.05) and } \\
\text { reduced macrophage } \\
\text { phagocytosis. } \\
\text { Autoradiographic studies } \\
\text { demonstrated that the } \\
\text { labeling indices of terminal } \\
\text { bronchiolar and lung } \\
\text { parenchymal cells were } \\
\text { generally increased in the } 50 \\
\text { and } 150 \text { mg/m3 groups after } \\
2 \text { and } 4 \text { weeks of exposure } \\
\text { but, with one exception, } \\
\text { returned to normal levels } \\
\text { following a } 3 \text {-month } \\
\text { postexposure period. }\end{array}$ & [143] \\
\hline
\end{tabular}


Table 3 In vivo studies on nanosilica particles (SNPs) toxicity (Continued)

\begin{tabular}{|c|c|c|c|c|c|c|}
\hline $\begin{array}{l}\text { Aerosol } \\
\text { containing } \\
\text { colloidal silica }\end{array}$ & $\begin{array}{l}\text { Average size: } \\
22 \mathrm{~nm}\end{array}$ & $\begin{array}{l}\text { - Mass median } \\
\text { aerodynamic } \\
\text { diameter }(2.9,3.3 \\
\text { and } 3.7 \mu \mathrm{m}) \\
\text { - Chamber } \\
\text { Ludox } \\
\text { concentration }\end{array}$ & $\begin{array}{l}\text { Rats inhalation (from } 10 \text { to } \\
150 \mathrm{mg} / \mathrm{m}^{3} \text { ), } 6 \mathrm{~h} / \text { day, } 5 \\
\text { days/week for } 4 \text { weeks; } 3 \\
\text { months postexposure }\end{array}$ & $\begin{array}{l}\text { - Lung silica determination } \\
\text { - Body weights and clinical } \\
\text { observations } \\
\text { - Clinical pathology (urine and } \\
\text { blood samples) } \\
\text { - Histopathology }\end{array}$ & $\begin{array}{l}\text { No effects after exposure to } \\
\text { the lowest concentration } \\
\text { Lung weights were increased } \\
\text { significantly after } 4 \text { exposure } \\
\text { to } 50 \text { and } 150 \mathrm{mg} / \mathrm{m}^{3} \text {. } \\
\text { A dose dependent alveolar } \\
\text { macrophage response, } \\
\text { polymorphonuclear leukocytic } \\
\text { infiltration, and Type Il } \\
\text { pneumocyte hyperplasia in } \\
\text { alveolar duct regions was } \\
\text { reported. } \\
\text { Lung-deposited nanosilica } \\
\text { cleared rapidly from the lungs } \\
\text { with half-times of } \\
\text { approximately } 40 \text { and } 50 \text { days } \\
\text { for the } 50 \text { and } 150 \text { mg/m }{ }^{3} \\
\text { groups, respectively. The } \\
\text { lungs did not show fibrotic } \\
\text { scar tissue formation or } \\
\text { alveolar bronchiolarization. }\end{array}$ & [52] \\
\hline Colloidal silica & $\begin{array}{l}\text { (UFCSs, } \\
\text { average size } \\
\text { of } 14 \mathrm{~nm} \text { ) } \\
\text { fine colloidal } \\
\text { silica particles } \\
\text { (FCSs; } \\
\text { average size } \\
\text { of } 213 \mathrm{~nm} \text { ) }\end{array}$ & $\begin{array}{l}\text { - Size } \\
\text { distribution } \\
\text { - Surface area } \\
\text { - Metal } \\
\text { composition }\end{array}$ & $\begin{array}{l}\text { Mice instilled intratracheally } \\
(3 \mathrm{mg}) \text { and sacrificed } 0.5,2, \\
6,12 \text { and } 24 \mathrm{~h} \text { after dosing }\end{array}$ & $\begin{array}{l}\text { - Histopathology } \\
\text { - Immunohistochemistry } \\
\text { - Electron microscopy }\end{array}$ & $\begin{array}{l}\text { Histopathological examination } \\
\text { revealed for both sizes } \\
\text { bronchiolar degeneration, } \\
\text { necrosis, neutrophilic } \\
\text { inflammation, alveolar type II } \\
\text { cell swelling and alveolar } \\
\text { macrophage accumulation. } \\
\text { UFCs induced extensive } \\
\text { alveolar hemorrhage, a more } \\
\text { severe bronchiolar epithelial } \\
\text { cell necrosis and neutrophil } \\
\text { influx in alveoli compared to } \\
\text { FCSs. } \\
\text { Electron microscopy } \\
\text { demonstrated UFCSs and } \\
\text { FCSs on bronchiolar and } \\
\text { alveolar wall surface as well } \\
\text { as in the cytoplasm of } \\
\text { alveolar epithelial cells, } \\
\text { alveolar macrophages and } \\
\text { neutrophils. } \\
\text { The findings suggest that } \\
\text { UFCSs (possibly linked to } \\
\text { larger surface area) have } \\
\text { greater ability to induce lung } \\
\text { inflammation and tissue } \\
\text { damages than FCSs. }\end{array}$ & [98] \\
\hline
\end{tabular}


Table 3 In vivo studies on nanosilica particles (SNPs) toxicity (Continued)

\begin{tabular}{|c|c|c|c|c|c|c|}
\hline Colloidal silica & $\begin{array}{l}\text { average size: } \\
14 \mathrm{~nm}\end{array}$ & $\begin{array}{l}\text { - Size } \\
\text { distribution } \\
\text { - Surface area } \\
\text { - Metal } \\
\text { composition }\end{array}$ & $\begin{array}{l}\text { Mice instilled intratracheally } \\
(0.3,3,10,30 \text { or } 100 \mu \mathrm{g}) \text { and } \\
\text { sacrificed } 3 \text { days after } \\
\text { dosing; } 1 \text { to } 30 \text { days } \\
\text { postexposure }\end{array}$ & $\begin{array}{l}\text { - BAL analysis: cells } \\
\text { quantification, viability and } \\
\text { differentiation, total protein } \\
\text { concentration } \\
\text { - Histopathology } \\
\text { - Immunohistochemistry } \\
\text { - Apoptosis (TUNEL assay) }\end{array}$ & $\begin{array}{l}\text { Exposure up to } 100 \mu \mathrm{g} \text { of } \\
\text { UFCSs produced moderate to } \\
\text { severe pulmonary } \\
\text { inflammation and tissue injury } \\
3 \text { days post exposure. } \\
\text { Mice instilled with } 30 \mu \mathrm{\mu g} \text { of } \\
\text { UFCSs and sacrificed at } \\
\text { intervals from } 1 \text { to } 30 \text { days } \\
\text { post-exposure showed } \\
\text { moderate pulmonary } \\
\text { inflammation and injury on } \\
\text { BALF indices at acute period; } \\
\text { however, these changes } \\
\text { gradually regressed with time. } \\
\text { Histopathological and } \\
\text { immunohistochemical } \\
\text { examination correlated to } \\
\text { BALF data. } \\
\text { A significant increase of the } \\
\text { apoptotic index (TUNEL) in } \\
\text { lung parenchyma at all } \\
\text { observation times was } \\
\text { reported. } \\
\text { The findings suggest that } \\
\text { instillation of a small dose of } \\
\text { UFCSs caused an acute, but } \\
\text { transient, lung inflammation } \\
\text { and tissue damage in which } \\
\text { oxidative stress and apoptosis } \\
\text { may be involved. }\end{array}$ & [146] \\
\hline $\begin{array}{l}\text { Amorphous } \\
\text { silica }\end{array}$ & $14 \mathrm{~nm}$ & $\begin{array}{l}\text { - Endotoxins } \\
\text { content }\end{array}$ & $\begin{array}{l}\text { Mice instilled intratracheally } \\
(2,10 \text { and } 50 \mathrm{mg} / \mathrm{kg}) \text { and } \\
\text { sacrificed } 24 \mathrm{~h}, 1,4 \text { and } 14 \\
\text { weeks after dosing }\end{array}$ & $\begin{array}{l}\text { - BAL analysis: total protein } \\
\text { and endotoxin concentration, } \\
\text { cell differential counts } \\
\text { - Histopathology } \\
\text { - Real-time PCR } \\
\text { - Immunohistochemistry }\end{array}$ & $\begin{array}{l}\text { Significantly increased lung } \\
\text { weights, total BAL cells and } \\
\text { proteins were observed until } \\
1 \text { week after treatment. } \\
\text { Particles induced acute } \\
\text { inflammation (with } \\
\text { neutrophils) at an early stage } \\
\text { and chronic granulomatous } \\
\text { inflammation at the later } \\
\text { stage. } \\
\text { The significant up-regulation } \\
\text { of cytokines (IL-1 } \beta \text {, IL-6, IL-8, } \\
\text { and TNF- } \alpha \text { ) and chemokines } \\
\text { (MCP-1 and MIP-2) was } \\
\text { observed during the early } \\
\text { stages, but there were no } \\
\text { changes after week } 1 . \\
\text { In conclusion, Instillation of } \\
\text { nanoparticles induced } \\
\text { transient but very severe lung } \\
\text { inflammation. }\end{array}$ & [144] \\
\hline
\end{tabular}


Table 3 In vivo studies on nanosilica particles (SNPs) toxicity (Continued)

\begin{tabular}{|c|c|c|c|c|}
\hline $\begin{array}{l}\text { Amorphous } \\
\text { silica }\end{array}$ & $\begin{array}{l}37.9 \pm 3.3 \\
n m\end{array}$ & $\begin{array}{l}\text { - Size } \\
\text { distribution } \\
\text { - Surface area } \\
\text { - Particle } \\
\text { number }\end{array}$ & $\begin{array}{l}\text { Rats inhalation ( } 24.1 \mathrm{mg} / \\
\mathrm{m}^{3}, 40 \mathrm{~min} / \text { day, } 4 \text { weeks } \\
\text { The age factor involved } 3 \\
\text { levels (young/ } \\
\text { adult/old) }\end{array}$ & $\begin{array}{l}\text { - Electrocardiography } \\
\text { - BAL analysis } \\
\text { - Hemorheological analysis } \\
\text { - Serum biomarker assay } \\
\text { - Pathology }\end{array}$ \\
\hline
\end{tabular}

Inhalation of SNP under

- Serum biomarker assay

identical conditions caused the strongest pulmonary and cardi ovascular alterations in old rats, yet less change in young and adult rats. Observed changes included pulmonary inflammation, myocardial ischemic damage, atrio-ventricular blockage, and increase in fibrinogen concentration and blood viscosity.

Old individuals were more sensitive to nanoparticle exposure

than the young and adult rats. The risk of causing pulmonary damages was: old > young > adult. The risk of cardiovascular disorder was observed only in old age.

\begin{tabular}{|c|c|c|c|c|}
\hline $\begin{array}{l}\text { Amorphous } \\
\text { silica }\end{array}$ & $\begin{array}{l}37 \mathrm{~nm} \text { and } \\
83 \mathrm{~nm}\end{array}$ & $\begin{array}{l}\cdot \text { The generation } \\
\text { of nanosilica } \\
\text { aerosol } \\
\text { - Size } \\
\text { distribution }\end{array}$ & $\begin{array}{l}\text { Rats inhalation } \\
\left(3.7 \times 10^{7} \text { or } 1.8 \times 10^{8}\right. \\
\left.\text { particles } / \mathrm{cm}^{3}\right), 6 \mathrm{~h} / \text { day, for } \\
\text { 1- or } 3 \text {-days } \\
\text { several post-exposure time } \\
\text { points (up to } 2 \text { months) }\end{array}$ & $\begin{array}{l}\text { - Bal analysis: cell counts, } \\
\text { differentials, enzymatic activity } \\
\text { of LDH,and ALP } \\
\text { - Genotoxicity endpoints } \\
\text { (micronuclei induction) }\end{array}$ \\
\hline
\end{tabular}

One- or three-day aerosol

exposure produced no significant pulmonary inflammatory, genotoxic, or adverse lung

histopathological effects in rats exposed to very high particle numbers corresponding to a range of mass concentrations (1.8 or $86 \mathrm{mg} / \mathrm{m}^{3}$ ).

\begin{tabular}{|c|c|c|c|}
\hline $\begin{array}{l}\text { Amorphous } \\
\text { silica }\end{array}$ & $14 \mathrm{~nm}$ & $\begin{array}{l}\text { O Daily mean } \\
\text { mass median } \\
\text { aerodynamic } \\
\text { diameter }(2.1 \pm \\
0.1 \mu \mathrm{m})\end{array}$ & $\begin{array}{l}\text { Rats inhalation } \\
\text { (head/nose only; } 26.9 \pm 3 \\
\left.\mathrm{mg} / \mathrm{m}^{3}\right), 6 \mathrm{~h} / \text { day during } 6 \\
\text { days); } \\
\text { Challenging the animals by } \\
\text { inhalation to a minimally } \\
\text { irritating concentration of } \\
\text { allergen trimellitic } \\
\text { anhydride (TMA) }\end{array}$ \\
\hline
\end{tabular}

Exposure to SNPs alone

- Breathing parameters

- Cellular and biochemical

changes in BAL

- Histopathological airway

resulted in transient changes

in breathing parameters

during exposure, and in nasal and alveolar inflammation with neutrophils and macrophages.

Exposure to particles before a single TMA challenge resulted in only a slightly irregular breathing pattern during TMA challenge. Pre-exposure to particles also diminished the effect of TMA on tidal volume, laryngeal ulceration, laryngeal inflammation, and the number of BAL

eosinophils in most animals. When the additional group of animals was exposed to nanosilica before a second challenge to TMA, the pulmonary eosinophilic infiltrate and edema induced by a second TMA challenge in control animals was diminished by the preceding silica exposure, but the number of lymphocytes in BAL was increased. 
Table 3 In vivo studies on nanosilica particles (SNPs) toxicity (Continued)

\begin{tabular}{lll}
\hline Amorphous & $\sim 30 \mathrm{~nm}$ and & . Size \\
silica & $\sim 30 \mu \mathrm{m}$ & distribution
\end{tabular}

Feeding of mice for 10

- Blood analysis

weeks (total fed amount of • Cytological analysis of lungs

$140 \mathrm{~g} / \mathrm{kg}$ mice) and liver tissue sections

- Analysis of silicon in organs
The nano-sized silica particle dieted group showed higher value of ALT (alanine

aminotransferase) than normal and micron-sized silica dieted groups.

H\&E staining of the liver of the nano-sized particle dieted group indicated some fatty liver pattern. The contents of $\mathrm{Si}$ in the livers of the groups were almost the same.

\begin{tabular}{|c|c|c|c|c|}
\hline $\begin{array}{l}\text { Amorphous } \\
\text { silica } \\
\text { (organically } \\
\text { modified) }\end{array}$ & $20-25 \mathrm{~nm}$ & $\begin{array}{l}\text { - Synthesis } \\
\text { - Conjugation } \\
\text { with fluorophore } \\
\text { - Radiolabelling }\end{array}$ & $\begin{array}{l}\text { Mice injected intravenously } \\
\text { with SPN } \\
\text { ( } 2.0 \mathrm{mg} / \mathrm{kg} \text { body weight) }\end{array}$ & $\begin{array}{l}\text { - Fluorescence imaging (C } \\
\text { - MicroPET imaging } \\
\text { - Histological Analysis }\end{array}$ \\
\hline
\end{tabular}

Greater acummulation of nanoparticles in liver, spleen and stomach that in kidney, heart and lungs.

Almost 100\% of the injected nanoparticles were effectively cleared out of the animals over a period of 15 days via the hepatobiliary excretion. No signs of organs toxicity were observed.

\begin{tabular}{|c|c|c|c|}
\hline $\begin{array}{l}\text { Amorphous } \\
\text { (mesoporous) } \\
\text { silica }\end{array}$ & $\begin{array}{l}150 \mathrm{~nm}, 800 \\
\mathrm{~nm} \text { and } 4 \\
\mu \mathrm{m} \\
\text { (pore sizes of } \\
3 \mathrm{~nm}, 7 \mathrm{~nm} \\
\text { and } 16 \mathrm{~nm} \text { ) }\end{array}$ & $\begin{array}{l}\text { - Synthesis } \\
\text { - Size } \\
\text { - Endotoxins } \\
\text { content }\end{array}$ & $\begin{array}{l}\text { Rats injected } \\
\text { subcutaneously ( } 30 \mathrm{mg} \text { per } \\
\text { rat), Mice injected } \\
\text { intraperitoneally and } \\
\text { intravenously }\end{array}$ \\
\hline
\end{tabular}

- Hematoxylin and eosin staining and histological examination

When the particles were injected subcutaneously, the amount of residual material decreased progressively over 3 months, with good biocompatibility on histology at all time points. Intra-peritoneal and intravenous injections in mice resulted in death or euthanasia. No toxicity was seen with subcutaneous injection of the same particles in mice.

Microscopic analysis of the lung tissue of the mice indicated that death may be due to thrombosis.

\begin{tabular}{|c|c|c|c|c|}
\hline $\begin{array}{l}\text { Amorphous } \\
\text { silica }\end{array}$ & $\begin{array}{l}75,311 \text { and } \\
830 \mathrm{~nm}\end{array}$ & Not specified & $\begin{array}{l}\text { Mice injected intravenously } \\
(10-100 \mathrm{mg} / \mathrm{kg})\end{array}$ & $\begin{array}{l}\text { - H\&E staining; histological } \\
\text { analysis of the liver, kidney, } \\
\text { spleen and lung } \\
\text { - Biochemical assays } \\
\text { - Gadolinium chloride, } \\
\text { cyclophosphamide and } \\
\text { hepatic hydroxyproline assay }\end{array}$ \\
\hline
\end{tabular}

$70 \mathrm{~nm}$ SNP induced liver injury at $30 \mathrm{mg} / \mathrm{kg}$ body weight, while SP300 or 1000 had no effect even at 100 $\mathrm{mg} / \mathrm{kg}$.

Administration of $70 \mathrm{~nm}$ SNP dose-dependently increased serum markers of liver injury, serum aminotransferase and inflammatory cytokines. Repeated administration of 70 $\mathrm{nm}$ SNP twice a week for 4 weeks, even at $10 \mathrm{mg} / \mathrm{kg}$, caused hepatic fibrosis. 
Table 3 In vivo studies on nanosilica particles (SNPs) toxicity (Continued)

\begin{tabular}{|c|c|c|c|c|c|}
\hline $\begin{array}{l}\text { Amorphous } \\
\text { silica }\end{array}$ & $\begin{array}{l}50,100 \text { and } \\
200 \mathrm{~nm}\end{array}$ & $\begin{array}{l}\text { - Synthesis } \\
\text { - Fluorescence } \\
\text { labeling }\end{array}$ & $\begin{array}{l}\text { Mice injected intravenously } \\
(50 \mathrm{mg} / \mathrm{kg})\end{array}$ & $\begin{array}{l}\text { - Confocal laser scanning } \\
\text { microscopy } \\
\text { - Immunofluorescence } \\
\text { staining } \\
\text { - Fluorescence microplate } \\
\text { readings }\end{array}$ & $\begin{array}{l}\text { Significant increase of } \\
\text { inflammation in the liver at } \\
12 \mathrm{~h} \text { for the } 100 \text { and } 200 \mathrm{~nm} \\
\text { silica nanoparticles treatment } \\
\text { groups. } \\
\text { The tissue distribution and } \\
\text { excretion of the injected } \\
\text { particles were different } \\
\text { depending on particle size. As } \\
\text { particle sizes increased, more } \\
\text { particles were trapped by } \\
\text { macrophages in the liver and } \\
\text { spleen. All particles were } \\
\text { cleared via urine and bile; } \\
\text { however, the } 50 \text { nm silica } \\
\text { nanoparticles excreted faster } \\
\text { than the other two particles. }\end{array}$ \\
\hline
\end{tabular}

cells was assessed by LDH and MTT assay; oxidative stress was studied by measurement of ROS, lipid peroxidation and GSH concentration; and apoptosis was quantified by annexin V/propidium iodide staining and DNA ladder assays. Nano- $\mathrm{SiO}_{2}$ caused cytotoxicity in a size-, dose- and time-dependent manner.

Because nanoparticles are probably distributed by the blood stream (e.g., with medical applications), endothelial cells would also come in direct contact with these particles, for pathogenic particle-endothelial interactions. Peters et al. [117] evaluated the effects of 4- to 40-nm amorphous $\mathrm{SiO}_{2}$ particles in vitro on human dermal microvascular endothelial cell function and viability. The particles were internalized but did not exert cytotoxic effects (MTS assay). However, cells showed impaired proliferative activity and pro-inflammatory stimulation. Napierska et al. [118] reported a dosedependent cytotoxicity (by MTT and LDH assay) of monodisperse amorphous SNPs $(16-335 \mathrm{~nm})$ in a human endothelial cell line. The toxicity of the particles was strongly related to particle size; smaller particles showed significantly higher toxicity and also affected the exposed cells faster. Ye et al. [119] evaluated the toxicity of amorphous SNPs (21 and $48 \mathrm{~nm}$ ) towards rat myocardial cells. Exposure to the SNPs for up to $48 \mathrm{~h}$ resulted in size-, dose- and time-dependent cytotoxicity, smaller particles again showing higher toxicity.

Barnes et al. [120] reported no detectable genotoxic activity (by Comet assay) of amorphous SNPs (20 nm to $<400 \mathrm{~nm}$ ) in 3T3-L1 fibroblasts at 4 or $40 \mu \mathrm{g} / \mathrm{ml}$ silica for $24 \mathrm{~h}$. The particle dispersions were carefully characterized and the results were independently validated in 2 separate laboratories. In a recent review, Gonzalez et al. [121], in a literature review, compared 2 genotoxicity tests - the alkaline Comet assay and the micronucleus test - in terms of chemical composition and size of engineered SNPs: engineered SNPs did not seem to induce DNA strand breakage. However, when monodisperse amorphous SNPs of 3 different sizes (16, 60 and $104 \mathrm{~nm}$ ) were selected to assess the genotoxic potential of these particles in A549 lung carcinoma cells with a well-validated assay (the in vitro cytochalasin-B micronucleus assay), at non-cytotoxic doses, the smallest particles showed an apparently higher-fold induction of micronucleated binucleated (MNBN) cells [122]. When considering the 3 SNPs together, particle number and total surface area accounted for MNBN induction because they were significantly associated with the amplitude of the effect.

\section{Crystalline nanosilica}

Wang et al. [99] investigated cytotoxicity (by MTT assay) and genotoxicity of ultrafine crystalline $\mathrm{SiO}_{2}$ particulates $\left(\mathrm{UF}-\mathrm{SiO}_{2}\right)$ in cultured human lymphoblastoid cells. A 24-h treatment with $120 \mu \mathrm{g} / \mathrm{ml}$ UF- $\mathrm{SiO}_{2}$ produced a fourfold increase in MNBN cells, with no significant difference as measured by the Comet assay. However, the ultrafine crystalline silica used was extracted from commercially available crystalline silica and the particle sizes were not uniform [99].

\section{Mesoporous silica}

The cytoxicity of amorphous mesoporous SNPs (MSNs) was recently studied intensively because they are promising materials for drug delivery systems and cell markers $[8,123,124]$. Several studies have demonstrated that efficient cellular uptake of MSNs could be achieved at concentrations $<50 \mu \mathrm{g} / \mathrm{ml}$, with no cytotoxic effects observed up to $100 \mu \mathrm{g} / \mathrm{ml}$ in different mammalian cells [125-130]. Lu et al. [128] reported on the optimal size of $\sim 50 \mathrm{~nm}$ MSNs for cell uptake. Slowing et al. [131] reported that, contrary to the known cytotoxicity of amorphous SNPs toward red blood cells, mesoporous SNPs exhibit high biocompatibility at concentrations adequate for potential pharmacological applications.

However, studies have reported cytotoxicity of mesoporous silica nanomaterials. Tao et al. [132] investigated the 
effects of two types of MSNs (pore diameters of 31 and 55 $\AA$ ) on cellular bioenergetics (cellular respiration and ATP content) in myeloid and lymphoid cells and isolated mitochondria. Only cells exposed to MSNs with larger size and larger pores showed concentration- and time-dependent inhibition of cellular respiration, and both nanoparticles were toxic to the isolated mitochondria. Di Pasqua et al. [133] reported that the toxicity of MSNs towards human neuroblastoma cells was related to the adsorptive surface area of the particle. However, the nature of the functional groups playing a role could not be excluded. Vallhov et al. [134] investigated the effects of mesoporous SNPs of different sizes $(270 \mathrm{~nm}$ and $2.5 \mu \mathrm{m})$ on human dendritic cells and found viability, uptake and immune regulatory markers affected by increasing size and dose. He et al. [135] evaluated the influence of size and concentration of mesoporous SNPs (190, 420 and $1220 \mathrm{~nm}$ ) on cytotoxicity in human breast cancer cells and monkey kidney cells. The cytotoxicity of the particles was associated with particle size: silica of 190 and $420 \mathrm{~nm}$ in diameter showed significant cytotoxicity at concentrations $>25 \mu \mathrm{g} / \mathrm{ml}$; whereas particles of $1220 \mathrm{~nm}$ in diameter showed slight cytotoxicity at $480 \mu \mathrm{g} / \mathrm{ml}$. The smaller particles were suggested to be more easily endocytosed and consequently located within lysosomes [135].

\section{Surface-modified/functionalized silica}

Brown et al. [136] attempted to evaluate the role of shape in particle toxicity in the lung; the authors compared the response of rod-shaped and spherical amorphous silica particles (Stöber), not coated or coated with fibronectin or polyethylene glycol (PEG), under stretched and static conditions. The dosimetric comparison of materials with different shapes (e.g., needleshaped or acicular and isotropic) was not straightforward. Non-coated particles induced an increase in IL-8 and LDH release, whereas a surface modification with PEG mitigated this effect, which suggested the significance of adhesive interactions for membrane binding/ signal transduction, for example [136].

Diaz et al. [137] described the interactions of two amorphous silica particles - a pristine particle, without any coating, and PEGylated silica particles (average size 130 and $155 \mathrm{~nm}$ ), as well as an iron oxide particle with a silica shell $(80 \mathrm{~nm})$ - with different human peripheral blood cells, several human tumor cell lines and mouse peritoneal macrophages. The effects depended on the cell analyzed: although all particles were phagocytosed and were able to induce ROS expression in mouse macrophages, they differentially affected the human cell lines and peripheral blood cells, both in terms of internalization and ROS induction. The availability of the particles to be internalized by the cells seemed to strongly depend on aggregation, especially on the size and morphology of the aggregates [137].
Almost all of the existing cytotoxicity studies of SNPs involved monocultures of cells that are organ specific. The exception is the study by Wottrich et al. [103], in which co-cultures of epithelial cells (A549) and macrophages (THP-1, Mono Mac 6) exposed to 60- and 100$\mathrm{nm}$ amorphous SNPs showed an increased sensitivity to the cytokine release as compared with monocultures of each cell type. The enhanced responses to nanoparticles in different contact and non-contact co-cultures were reported in studies by Herseth et al. $[138,139]$ with micron-sized crystalline silica, showing that more realistic models should be applied to study interactions between nanoparticles and cells or organs of interest.

Few recently published studies have systematically investigated nanomaterial properties in terms of the degree and pathways of cytotoxicity. Sohaebuddin et al. [140] selected nanomaterials of different composition, including silica, to analyze the effects of size and composition on 3 model cell lines: fibroblasts, macrophages and bronchiolar epithelial cells. The authors concluded that the physico-chemical properties of size and composition both determined the cellular responses and induced cellspecific responses. In another recent study, Rabolli et al. [141] studied the influence of size, surface area and microporosity on the in vitro cytotoxic activity of a set of 17 stable suspensions of monodisperse amorphous SNPs of different sizes $(2-335 \mathrm{~nm})$ in 4 different cell types (macrophages, fibroblasts, endothelial cells and erythrocytes). The response to these nanoparticles was governed by different physico-chemical parameters that varied by cell type: in murine macrophages, the cytotoxic response increased with external surface area and decreased with micopore volume; in human endothelial cells and mouse embryo fibroblasts, the cytotoxicity increased with surface roughness and decrease in diameter; and in human erythrocytes, the hemolytic activity increased with the diameter of the SNP [141].

Overall, most of these in vitro studies involving different SNPs documented the cytotoxic effects of these nanomaterials. The determinants of the observed cytotoxicity seem to be complex and vary with the particles used and cell type tested. Unfortunately, for many published studies, adequate material characterization is still missing. The mere cytotoxicity reported with some particles does not strictly imply hazard. However, this observation indicates that a proactive development of nanomaterials should consider physical, chemical and catalytic properties of nanoparticles.

\section{In vivo studies of nanosilica toxicity}

Along with particle size, surface area and particle number appear to be integral components contributing to the mechanisms of lung toxicity induced by nano-sized particles. The high deposition rate of ultrafine particulates is a 
result of a small aerodynamic diameter and is assumed to be important in the lung inflammatory process. Some evidence suggests that inhaled nanoparticles, after deposition in the lung, largely escape from alveolar macrophage clearance and gain greater access to the pulmonary interstitium via translocation from alveolar spaces through epithelium [3,142]. A summary of the in vivo responses to SNPs can be found in Table 3.

In 1991, Warheit et al. [143] performed a rat inhalation study (nose-only) with an aerosol of colloidal silica (mass median aerodynamic diameter 2.9, 3.3 and $3.7 \mu \mathrm{m}$ ) for 2 or 4 weeks at concentrations up to 150 $\mathrm{mg} / \mathrm{m}^{3}$, and some groups of rats were allowed to recover for 3 months. The inflammatory responses, mainly seen as increased numbers of neutrophils in bronchoalveolar lavage fluid (BALF), with the 2 and/or 4 weeks of exposure were evident at $\geq 50 \mathrm{mg} / \mathrm{m}^{3}$ concentration. Three months after exposure, most biochemical parameters returned to control values [143].

Lee and Kelly [52] studied the effects of repeated inhalation ( 6 h/day, 5 days/week for 4 weeks) of an aerosol of colloidal silica (mass median aerodynamic diameter 2.9, 3.3 and $3.7 \mu \mathrm{m}$; concentration up to $150 \mathrm{mg} / \mathrm{m}^{3}$ ) in rats. The authors reported a dose-dependent alveolar macrophage response, polymorphonuclear leukocytic infiltration, and type II pneumocyte hyperplasia in alveolar duct regions. Lung-deposited nanosilica were cleared rapidly from the lungs, with half-times of approximately 40 and 50 days for the 50 and $150 \mathrm{mg} / \mathrm{m}^{3}$ treatment groups, respectively. The lungs did not show formation of fibrotic scar tissue or alveolar bronchiolarization [52].

Cho et al. [144] investigated inflammatory mediators ( $24 \mathrm{~h}$, and 1,4 or 14 weeks after exposure) induced by intratracheal instillation in mice of up to $50 \mathrm{mg} / \mathrm{kg}$ of ultrafine amorphous silica with a primary particle diameter of $14 \mathrm{~nm}$. The authors observed significantly increased lung weights, total cell numbers and levels of total protein in BALF up to 1 week after treatment. The histopathological examination revealed acute inflammation, with neutrophils and chronic granulomatous inflammation. The expression of cytokines (IL-1 $\beta$, IL-6, IL-8, and TNF- $\alpha$ ) and chemokines (monocyte chemoattractant protein 1 and macrophage inflammatory protein 2) was significantly increased during the early stages, with no changes after week 1 [144].

Chen et al. [145] studied age-related differences in response to amorphous SNPs (average size $38 \mathrm{~nm}$ ). Changes in serum biomarkers, pulmonary inflammation, heart injury and pathology were compared in young (3 weeks), adult ( 8 weeks) and old (20 months) rats that inhaled tested nanoparticles for 4 weeks ( $40 \mathrm{~min} /$ day). Old animals appeared to be more sensitive to nanoparticle exposure than were young and adult rats. The risk of pulmonary damage was old > young > adult, but the risk of cardiovascular disorder was observed only in old animals [145].

Kaewamatawong et al. [98] compared acute pulmonary toxicity induced in mice by ultrafine colloidal silica particles (UFCSs; average size $14 \mathrm{~nm}$ ) or fine colloidal silica particles (FCSs; average size $213 \mathrm{~nm}$ ) after intratracheal instillation of 3-mg particles. Histopathological examination with both sizes revealed bronchiolar degeneration, necrosis, neutrophilic inflammation, alveolar type II cell swelling and alveolar macrophage accumulation. However, UFCSs induced extensive alveolar hemorrhage, more severe bronchiolar epithelial cell necrosis and neutrophil influx in alveoli as compared with FCSs. Electron microscopy showed UFCSs and FCSs on the bronchiolar and alveolar wall surface and in the cytoplasm of alveolar epithelial cells, alveolar macrophages and neutrophils. The findings suggest that UFCSs (possibly linked to size and/or larger surface area) have a greater ability to induce lung inflammation and tissue damage than do FCSs [98]. The same research group reported acute and subacute pulmonary toxicity of low-dose UFCS particles in mice after intratracheal instillation [146]. Exposure of up to $100 \mu \mathrm{g}$ UFCSs produced moderate to severe pulmonary inflammation and tissue injury 3 days after exposure. Mice instilled with $30 \mu \mathrm{g}$ UFCSs and sacrificed at intervals from 1 to 30 days after exposure showed moderate pulmonary inflammation and injury on BALF indices at the acute period; however, these changes gradually regressed with time. Concomitant histopathological and laminin immunohistochemical results were similar to BALF data. The authors reported a significant increase in the apoptotic index (TUNEL) in lung parenchyma at all observation times. The findings suggest that instillation of a small dose of UFCSs causes acute but transient lung inflammation and tissue damage in which oxidative stress and apoptosis may be involved [146].

In a study of fibrogenesis, Wistar rats were intratracheally instilled with silica (of unknown composition) nano- $(10 \pm 5 \mathrm{~nm})$ and microparticles $(0.5-10 \mu \mathrm{m})$, and were sacrificed 1 and 2 months after dosing [147]. One month after instillation, cellular nodules (Stage I silicosis) were found in the nano-sized $\mathrm{SiO}_{2}$ group, whereas more severe lesions were found in the micron-sized $\mathrm{SiO}_{2}$ treatment group (Stage II and Stage II+ of silicotic nodules). One month later, the nano-sized $\mathrm{SiO}_{2}$ group still showed only Stage I silicotic nodules, whereas the micron-silica group showed disease progression and Stage II+ and III silicotic nodules. Therefore, in rats, the effect of nano- $\mathrm{SiO}_{2}$ on fibrogenesis might be milder than that of micron- $\mathrm{SiO}_{2}$. Nanoparticles, because of their size, probably diffuse more easily to other pulmonary compartments than do microparticles [147]. 
Warheit et al. [148] compared the toxicity of synthetic nanoquartz particles (12 and $50 \mathrm{~nm}$ ) to mined Min-USil quartz $(500 \mathrm{~nm})$ and synthetic fine-quartz particles $(300 \mathrm{~nm})$ and (2) evaluated the surface activity (hemolytic potential) of the different samples in terms of toxicity. Rats were instilled with the different particle types (1 or $5 \mathrm{mg} / \mathrm{kg}$ ), and pulmonary toxicity was assessed with BALF biomarkers, cell proliferation, and histopathological evaluation of lung tissue at $24 \mathrm{~h}, 1$ week, 1 month, and 3 months after exposure. Exposure to the quartz particles of different sizes produced pulmonary inflammation and cytotoxicity, with nanoscale quartz of $12 \mathrm{~nm}$ and Min-U-Sil quartz being more toxic than fine quartz and nanoscale quartz of $50 \mathrm{~nm}$. The pulmonary effects were not consistent with particle size but were associated with surface activity, particularly hemolytic potential [148].

In a recent work by Sayes et al. [149], rats inhaled freshly generated aerosolized amorphous SNPs of 37 and $83 \mathrm{~nm}$ for a short-term period. In contrast to previous studies' measurements, particle number rather than particle mass was chosen as dose metrics $(3.7 \times$ $10^{7}$ or $1.8 \times 10^{8}$ particles $/ \mathrm{cm}^{3}$ ) for 1 - or 3 -day exposure. Pulmonary toxicity (cell counts, differentials, enzymatic activity of LDH and alkaline phosphatase (ALP) in BALF) and genotoxicity endpoints (micronuclei induction) were assessed from $24 \mathrm{~h}$ up to 2 months after exposure. One- or 3-day aerosol exposure produced no significant pulmonary inflammatory, genotoxic or adverse lung histopathological effects in rats exposed to very high particle numbers in a range of mass concentrations $\left(1.8\right.$ or $\left.86 \mathrm{mg} / \mathrm{m}^{3}\right)$.

Recently, airway irritants were suggested to facilitate allergic sensitization [150-152]. Arts et al. [153] examined the effect of pre-exposure to synthetic (fumed) amorphous SNPs $(14 \mathrm{~nm})$ on elicitation of airway hypersensitivity reactions by the low-molecular-weight allergen trimellitic anhydride (TMA). Brown Norway rats were topically sensitized with TMA, exposed (head or nose only) to SNPs for $6 \mathrm{~h}$ /day for 6 days and then challenged by inhalation with a minimally irritating concentration of TMA. One day later, breathing parameters, cellular and biochemical changes in BALF, and histopathological airway changes were studied. Exposure to SNPs alone resulted in transient changes in breathing parameters during exposure and in nasal and alveolar inflammation with neutrophils and macrophages. Exposure to particles before a single TMA challenge resulted in only a slightly irregular breathing pattern during TMA challenge. Interestingly, pre-exposure to particles diminished the effect of TMA on tidal volume, laryngeal ulceration, laryngeal inflammation, and the number of BALF eosinophils in most animals. When an additional group of animals was exposed to nanosilica before a second challenge to TMA, the pulmonary eosinophilic infiltrate and edema induced by a second TMA challenge in control animals was diminished by the preceding silica exposure, but the number of lymphocytes in the BALF was increased. The authors concluded that SNPs could reduce as well as aggravate certain aspects of TMA-induced respiratory allergy [153].

As mentioned, next to inhalation, ingestion is considered a major route for the uptake of nanoparticles in the human body. So et al. [154] studied the effects on mice fed nano- and micron-sized amorphous silica particles (30 $\mathrm{nm}$ and approximately $30 \mu \mathrm{m}$, respectively). After feeding the animals for 10 weeks (total amount of $140 \mathrm{~g}$ silica/kg mouse), blood was tested biochemically and hematologically. The group fed SNPs showed higher serum values of alanine aminotransferase as compared with the other groups (both control and micron-silica treated). Although the contents of Si in the livers of the groups were almost the same, hematoxylin and eosin staining revealed a fatty liver pattern in the group treated with SNPs [154].

The successful use of nanoparticles in the clinic requires exhaustive studies on the behavior of these particles in vivo. Unfortunately, biocompatibility, biodistribution and clearance studies of silica-based nanoparticles are sparse. Kumar et al. [155] used nanoparticles of organically modified amorphous silica (ORMOSIL; amino-terminated; 20-25 nm) to study biodistribution, clearance and toxicity in a mouse model. Particles conjugated with fluorophore and radiolabeled were injected systemically in mice. Biodistribution studies showed a greater accumulation of nanoparticles in liver, spleen and stomach than in kidney, heart and lungs. Over 15 days, almost $100 \%$ of the injected nanoparticles were effectively cleared out of the animals via hepatobiliary excretion, without any sign of organ toxicity. Hudson et al. [156] examined the biocompatibility of mesoporous silica particles $(150 \mathrm{~nm}, 800 \mathrm{~nm}$ and $4 \mu \mathrm{m})$ after injection in rats and mice. When the particles were injected subcutaneously in rats, the amount of residual material decreased progressively over 3 months, with no significant injury to surrounding tissues. Subcutaneous injection of the same particles in mice produced no toxic effects. In contrast, intra-peritoneal and intravenous injection in mice resulted in death; microscopic analysis of the lung tissue of the mice indicated that death might have been due to pulmonary thrombosis. Nishimori et al. [157] evaluated the acute toxicity of amorphous silica particles (70, 300 and $1000 \mathrm{~nm}$ ) after a single intravenous injection in mice and reported that 70-nm silica injured the liver but not the spleen, lung or kidney. Moreover, chronic administration of 70-nm nanoparticles (injections every 3 days for 4 weeks) caused liver fibrosis. Cho et al. [158] examined the 
impact of the size of amorphous SNPs on toxicity, tissue distribution and excretion. Fluorescence dye-labeled 50-, 100- and 200-nm silica particles were intravenously injected in mice. The incidence and severity of inflammation with the 100- and 200-nm SNPs was significantly increased in the liver at $12 \mathrm{~h}$; the 50 -nm particles induced a slight but nonsignificant inflammatory response. The tissue distribution and excretion of the injected particles differed depending on particle size. With increasing particle size, more particles were trapped by macrophages in the liver and spleen. All particles were cleared via urine and bile; however, the 50$\mathrm{nm}$ SNPs were excreted faster than were the other 2 particle sizes [158].

\section{In vivo versus in vitro; amorphous versus crystalline}

Park and Park [159] performed in vitro and in vivo studies to investigate oxidative stress and pro-inflammatory responses induced by amorphous SNPs (average primary size $12 \mathrm{~nm}$ ). RAW 264.7 cells derived from mouse peritoneal macrophages were exposed to SNPs (5-40 $\mathrm{ppm})$ in vitro and showed ROS generation and decreased intracellular GSH levels, as well as increased levels of nitric oxide released from the cultured macrophage cell line. In vivo, mice were treated with a single intraperitoneal dose of $50 \mathrm{mg} / \mathrm{kg}$ of nanosilica. The treatment produced activated peritoneal macrophages, increased blood level of IL- $1 \beta$ and TNF- $\alpha$, and increased level of nitric oxide released from peritoneal macrophages. Ex vivo, cultured peritoneal macrophages harvested from the treated mice showed the expression of inflammation-related genes (IL-1, IL-6, TNF- $\alpha$, inducible nitric oxide synthase, cyclooxygenase 2 ). In the spleen, the relative distribution of natural killer cells and $\mathrm{T}$ cells was increased $184.8 \%$ and $115.1 \%$, respectively, as compared with control animals, and that of B cells was decreased to $87.7 \%$ [159].

Kim et al. [160] addressed the toxicity of nano- and micron-sized silica particles $(14 \mathrm{~nm}$ and $1-5 \mu \mathrm{m}$, respectively) in vitro and in vivo. In vitro, RAW 264.7 cells were exposed to both particle sizes for $24 \mathrm{~h}$, and the cell viability was decreased in dose-dependent manner; however, apoptosis was observed only after treatment with nanoparticles. In vivo, mice received up to $5 \mathrm{mg} / \mathrm{kg}$ silica particles via oropharyngeal aspiration. Again, sizedependent toxicity of silica was observed; pulmonary injury and neutrophilic infiltration were greater after treatment with nano-sized $\mathrm{SiO}_{2}$ particles than with micron-sized silica [160].

Sayes et al. [161] assessed the capacity of in vitro screening studies to predict in vivo pulmonary toxicity of several fine or nanoscale particle types in rats. For the in vitro component of the study, rat lung epithelial cells, primary alveolar macrophages and alveolar macrophages- lung epithelial cell co-cultures were incubated with quartz particles and precipitated amorphous silica. In the in vivo component of the study, rats were exposed by intratracheal instillation to the same particles. In vivo, pulmonary toxicity studies demonstrated that crystalline silica particles produced sustained inflammation and cytotoxicity, whereas amorphous silica particles produced reversible and transient inflammatory responses. Ex vivo, pulmonary inflammation studies showed that crystalline and amorphous silica-exposed rat lung epithelial cells did not produce MIP-2 cytokines, but alveolar macrophages and, to a lesser degree, co-cultures secreted this chemotactic factor into the culture media. In vitro cytotoxicity studies demonstrated a variety of responses to the different particle types, primarily at high doses. When considering the range of toxicological endpoints, comparisons of in vivo and in vitro measurements revealed little correlation, particularly when considering the many variables assessed in this study such as cell types used, culture conditions and time course of exposure, as well as measured endpoints.

To summarize, extrapolating (or comparing) the results obtained in vitro to the in vivo situation is difficult and applies not only to toxicity studies with nanoparticles any existing in vitro test system lacks the complexity of animal models or the human body. However, considering the number of particles and the number of possible properties of these particles that may vary (size, shape, coating, etc.), clearly, not all can be evaluated in in vivo studies, and scientists have been striving to determine the correlation between the results obtained from in vitro and in vivo toxicity assessments. Although little correlation has been found in these studies with nanosilica [159-161], Lu et al. [162] tested a panel of metal oxide nanoparticles and could predict the inflammogenicity of tested nanomaterials with a battery of simple in vitro tests. Similar conclusions were drawn in a recent study by Rushton et al. [163]; the authors could predict the acute in vivo inflammatory potential of nanoparticles with cell-free and cellular assays by using NP surface area-based dose and response metrics. The authors also found that a cellular component was required to achieve a higher degree of predictive power.

Established and validated co-culture systems may provide a tool to better mimic the in vivo system. Using recently developed 3-D cell cultures and improving the exposure system (likewise exposure at the air-liquid interface of a human epithelial airway model reported by Brandenberger et al. [164]), could substantially improve the outcome from in vitro studies with nanomaterials.

\section{Conclusions}

Silica or silicon dioxide $\left(\mathrm{SiO}_{2}\right)$ is, in many forms, abundantly present in our natural environment. The adverse 
health effects, including lung cancer, of naturally occurring crystalline silica such as quartz and cristobalite have been thoroughly documented in occupational settings. Naturally occurring amorphous silica such as diatomaceous earth is considered less harmful. Most of the synthetic (manufactured) silicas used in a large variety of applications are amorphous. For silica in general, the property most significantly linked to the toxicological potential is the crystallinity. For micron-sized crystalline silica, oxidative stress and, linked to it, oxidative DNA and membrane damage, are probably the most important mechanisms involved in the inflammogenic and fibrogenic activities (reviewed by [60]) and/or carcinogenic activity $[39,165]$, for example. These mechanisms do not apply to amorphous silica, which has therefore been far less studied. Moreover, the adverse health effects of biogenic (natural) amorphous silica is often attributed to a certain degree of contamination with crystalline silica [49]. Synthetic amorphous silica (colloidal silica, fumed silica and precipitated silica) is not involved in progressive fibrosis of the lung [52,53]; however, high doses of amorphous silica may result in acute pulmonary inflammatory responses [54].

Interest in using SNPs is growing worldwide, especially for biomedical and biotechnological applications such as cancer therapy, DNA transfection, drug delivery, and enzyme immobilization [5-9]. In general, SNPs are synthetic, which has an advantage over natural silica in that they contain fewer or no impurities than do natural silica, and the physico-chemical properties are known and well controlled during production. Exposure to SNPs during the production process and their downstream use is probably minimal for sols and gels because the nanoparticles are trapped/immobilized within their matrix. However, the inhalation potential of low-density fumed silica powders or freeze-dried nanoparticles may be high without adequate precautions.

Results of a growing number of in vitro studies indicate that the particle surface area may play a crucial role in the toxicity of silica $[75,166]$. The cytotoxic activity of silica particles can be related to their surface interfacing with the biological milieu rather than to particle size or shape [75]. Surface silanol groups are directly involved (as shown in vitro) in hemolysis [76-78] and in alveolar epithelial cell toxicity $[79,80]$. This observation indirectly links the hydrophilicity to cellular toxicity $[80,81]$. The size and surface physico-chemical features of SNPs contribute decisively to the biological effects of $\mathrm{SiO}_{2}$ nanoparticles. The complexity of protein-SNP interactions should not be underestimated; these interactions appear to be affected by the size of SNPs as well [167-171]. The effect of other physico-chemical properties of SNPs on health, such as porosity, chemical purity, surface chemistry and solubility, are less well studied, and therefore no definite conclusions can be formulated (summary of the data can be found in Table 2). Comparison of published studies leads to the conclusion that even a small modification of the surface can result in a more or less marked change of a biological effect $[2,3,172]$. Few in vitro studies have emphasized that the response to SNPs varies by cell type $[137,140,141]$.

Considering the use of SNPs for medical applications, biocompatibility and toxicokinetics need to be documented in great detail because, despite no observation of acute (cyto)toxicity, the uptake of the particles by cells may eventually lead to perturbation of intracellular mechanisms. For instance, the ability of silica-coated nanomaterials to penetrate the blood-brain barrier supports the urgent need for extensive studies to clarify the potential chronic toxicity of these materials [14]. The successful use of nanoparticles in the clinic requires exhaustive and elaborate in vivo studies [155]. Of note, the toxicity of SNPs can depend on not only the material itself but also the administration route to the living body, as was shown by Hudson et al. [156]: subcutaneous injection presented good biocompatibility, whereas intraperitoneal and intravenous injection led to fatal outcomes.

Unfortunately, only limited short-term and no chronic in vivo studies of SNPs are available (summary of the data is found in Table 3), and the current data do not clarify whether amorphous SNPs - showing augmented cytotoxicity and presumably processing oxidative DNA damaging potential - are less or more harmful as compared with micron-sized silica.

Determining the association of results from in vitro and in vivo toxicity assessments is difficult; however, the common feature seems to be cytotoxicity and inflammatory response after exposure to SNPs.

To conclude, the available studies of the toxicity of SNPs are relatively few, especially as compared to the vast number of studies of titanium dioxide or carbon nanotubes. Besides the relative lack of information on the safety or hazards of SNPs, often conflicting evidence is emerging in the literature as a result of a general lack of standard procedures, as well as insufficient characterization of nanomaterials in biological systems. For all studies, a crucial issue remains the careful, accurate characterization of particle size and morphologic features (especially in the biological media used for experimental set-up), composition, particle surface area and surface chemistry [173]. Moreover, equally important to the physico-chemical characterization of the material is the control of assays and assay conditions [174,175]. Only with the complete description of the NP and assay can the results of reported studies be comparable with those of other studies conducted with similar nanomaterials $[159,176]$. 
Until now, the health effects of SNPs have mainly been studied in terms of exposure via the respiratory tract, after acute or sub-acute exposure; other exposure routes should also be checked (e.g. blood, skin, gastrointestinal tract). Studies of chronicity are needed to supplement and verify the existing data. Information is insufficient to clearly identify and characterize the health hazards SNPs pose, and defining the appropriate conditions for safe use of these materials is currently not possible.

\section{Acknowledgements}

This work was supported by the Belgian Science Policy program "Science for a Sustainable Development" (SD/HE/02A). JAM acknowledges the Flemish government for long-term structural funding (Methusalem).

\section{Author details}

'Unit of Lung Toxicology, Katholieke Universiteit Leuven, Herestraat 49, 3000 Leuven, Belgium. ${ }^{2}$ Center for Surface Chemistry and Catalysis, Katholieke Universiteit Leuven, Kasteelpark Arenberg 23, 3001 Heverlee, Belgium. ${ }^{3}$ Louvain centre for Toxicology and Applied Pharmacology (LTAP), Université Catholique de Louvain, Avenue E. Mounier, 53.02, 1200 Brussels, Belgium.

\section{Authors' contributions}

DN, LCJT and PHH drafted the manuscript. DN provided key input in the literature search. LCJT and JAM wrote the section on synthesis and characterization of silica materials. LCJT prepared all figures. DL contributed to drafting the paper. All authors read and approved the final manuscript.

\section{Competing interests}

The authors declare that they have no competing interests.

Received: 24 June 2010 Accepted: 3 December 2010 Published: 3 December 2010

\section{References}

1. Kreyling WG, Semmler-Behnke M, Chaudhry Q: A complementary definition of nanomaterial. Nano Today 2010, 5:165-168.

2. Oberdorster G, Maynard A, Donaldson K, Castranova V, Fitzpatrick J, Ausman K, Carter J, Karn B, Kreyling W, Lai D, Olin S, Monteiro-Riviere N, Warheit D, Yang H: Principles for characterizing the potential human health effects from exposure to nanomaterials: elements of a screening strategy. Part Fibre Toxicol 2005, 2:8

3. Oberdorster G, Oberdorster E, Oberdorster J: Nanotoxicology: an emerging discipline evolving from studies of ultrafine particles. Environ Health Perspect 2005, 113:823-839.

4. Powers KW, Brown SC, Krishna VB, Wasdo SC, Moudgil BM, Roberts SM: Research strategies for safety evaluation of nanomaterials. Part VI. Characterization of nanoscale particles for toxicological evaluation. Toxicol Sci 2006, 90:296-303.

5. Hirsch LR, Stafford RJ, Bankson JA, Sershen SR, Rivera B, Price RE, Hazle JD, Halas NJ, West JL: Nanoshell-mediated near-infrared thermal therapy of tumors under magnetic resonance guidance. Proc Natl Acad Sci USA 2003, 100:13549-13554.

6. Moghimi SM, Hunter AC, Murray JC: Nanomedicine: current status and future prospects. FASEB J 2005, 19:311-330.

7. Ravi Kumar MNV, Sameti M, Mohapatra SS, Kong X, Lockey RF, Bakowsky U, Lindenblatt G, Schmidt CH, Lehr M: Cationic Silica Nanoparticles as Gene Carriers: Synthesis, Characterization and Transfection Efficiency In vitro and In vivo. Journal of Nanoscience and Nanotechnology 2004, 4:876-881.

8. Slowing II, Vivero-Escoto JL, Wu CW, Lin VS: Mesoporous silica nanoparticles as controlled release drug delivery and gene transfection carriers. Adv Drug Deliv Rev 2008, 60:1278-1288.

9. Vijayanathan $\mathrm{V}$, Thomas T, Thomas TJ: DNA nanoparticles and development of DNA delivery vehicles for gene therapy. Biochemistry 2002, 41:14085-14094.
10. Barik TK, Sahu B, Swain V: Nanosilica-from medicine to pest control. Parasitol Res 2008, 103:253-258.

11. Maynard AD, Aitken RJ, Butz T, Colvin V, Donaldson K, Oberdorster G, Philbert MA, Ryan J, Seaton A, Stone V, Tinkle SS, Tran L, Walker NJ, Warheit DB: Safe handling of nanotechnology. Nature 2006, 444:267-269.

12. Panessa-Warren BJ, Warrren JB, Maye MM, Schiffer W: Nanoparticle Interactions with Living Systems: In Vivo and In Vitro Biocompatibility. In Nanoparticles and Nanodevices in Biological Applications Edited by: Stefano Bellucci. Berlin Heidelberg: Springer 2008, 1-45.

13. Salata O: Applications of nanoparticles in biology and medicine. $J$ Nanobiotechnology 2004, 2:3.

14. Kim JS, Yoon TJ, Yu KN, Kim BG, Park SJ, Kim HW, Lee KH, Park SB, Lee JK, Cho MH: Toxicity and tissue distribution of magnetic nanoparticles in mice. Toxicol Sci 2006, 89:338-347.

15. Iler RK: The Chemistry of Silica: Solubility, Polymerization, Colloid and Surface Properties and Biochemistry of Silica New York: Wiley; 1979.

16. Stöber W, Fink W, Bohn E: Controlled growth of monodisperse silica spheres in the micron size range. J Colloid Interface Sci 1968, 26:62-69.

17. Kresge CT, Leonowicz ME, Roth WJ, Vartuli JC, Beck JS: Ordered Mesoporous Molecular-Sieves Synthesized by A Liquid-Crystal Template Mechanism. Nature 1992, 359:710-712.

18. Zhao D, Feng J, Huo Q, Melosh N, Fredrickson GH, Chmelka BF, Stucky GD: Triblock copolymer syntheses of mesoporous silica with periodic 50 to 300 angstrom pores. Science 1998, 279:548-552.

19. Legrand AP: The Surface Properties of Silicas John Wiley \& Sons, Ltd. (UK); 1998.

20. Heaney PJ: Structure and Chemistry of the Low-Pressure Silica Polymorphs. In Silica: physical behanior, geochemistry, and materials applications. Edited by: Heaney PJ, Prewitt CT, Gibbs GV. Washington, D.C.: Mineralogical Society of America; 1994:1-40.

21. Liebau F: Structural Chemistry of Silicates. Structure, Bonding, and Classification Berlin: Springer-Verlag; 1985.

22. Baerlocher Ch, McCusker LB, Olson DH: Atlas of Zeolite Framework Types Amsterdam: Elsevier; 2007.

23. Barrer RM: Hydrothermal Chemistry of Zeolites London: Academic Press; 1982.

24. Higgins JB: Silica zeolites and clathrasils. In Silica: physical behanior, geochemistry, and materials applications. Edited by: Heaney PJ, Prewitt CT, Gibbs GV. Washington, D.C.: Mineralogical Society of America; 1994:507-543.

25. Tosheva L, Valtchev VP: Nanozeolites: Synthesis, Crystallization Mechanism, and Applications. Chem Mater 2005, 17:2494-2513.

26. Nel A, Xia T, Madler L, Li N: Toxic potential of materials at the nanolevel. Science 2006, 311:622-627.

27. McCusker LB, Liebau F, Engelhardt G: Nomenclature of structural and compositional characteristics of ordered microporous and mesoporous materials with inorganic hosts - (IUPAC recommendations 2001). Pure and Applied Chemistry 2001, 73:381-394.

28. McNaught AD, Wilkinson A: Compendium of Chemical Terminology Oxford: Blackwell Science; 1997.

29. Vanblaaderen A, Kentgens APM: Particle Morphology and Chemical Microstructure of Colloidal Silica Spheres Made from Alkoxysilanes. Journal of Non-Crystalline Solids 1992, 149:161-178.

30. Ghiazza M, Polimeni M, Fenoglio I, Gazzano E, Ghigo D, Fubini B: Does vitreous silica contradict the toxicity of the crystalline silica paradigm? Chem Res Toxicol 2010, 23:620-629.

31. Vogelsberger W, Schmidt J, Roelofs F: Dissolution kinetics of oxidic nanoparticles: The observation of an unusual behaviour. Colloids and Surfaces A-Physicochemical and Engineering Aspects 2008, 324:51-57.

32. Hessel PA, Sluis-Cremer GK: Silica, silicosis, and lung cancer among ceramic workers: a case-referent study. Am J Ind Med 1987, 12:219-222.

33. Hnizdo E, Sluis-Cremer GK: Risk of silicosis in a cohort of white South African gold miners. Am J Ind Med 1993, 24:447-457.

34. Hnizdo E, Murray J: Risk of pulmonary tuberculosis relative to silicosis and exposure to silica dust in South African gold miners. Occup Environ Med 1998, 55:496-502.

35. Calvert GM, Rice FL, Boiano JM, Sheehy JW, Sanderson WT: Occupational silica exposure and risk of various diseases: an analysis using death certificates from 27 states of the United States. Occup Environ Med 2003, 60:122-129.

36. Checkoway $\mathrm{H}$ : Epidemiological evidence on the carcinogenicity of silica: factors in scientific judgement. Ann Occup Hyg 2000, 44:483-484. 
37. Park R, Rice F, Stayner L, Smith R, Gilbert S, Checkoway $H$ : Exposure to crystalline silica, silicosis, and lung disease other than cancer in diatomaceous earth industry workers: a quantitative risk assessment. Occup Environ Med 2002, 59:36-43.

38. Soutar CA, Robertson A, Miller BG, Searl A, Bignon J: Epidemiological evidence on the carcinogenicity of silica: factors in scientific judgement. Ann Occup Hyg 2000, 44:3-14

39. IARC Working Group on the Evaluation of Carcinogenic Risks to Humans. Silica, some silicates, coal dust and para-aramid fibrils. 1997, 68:1-475.

40. Straif K, brahim-Tallaa L, Baan R, Grosse $Y$, Secretan B, El GF, Bouvard V, Guha N, Freeman C, Galichet L, Cogliano V: A review of human carcinogens-part C: metals, arsenic, dusts, and fibres. Lancet Oncol 2009, 10:453-454.

41. Checkoway $H$, Franzblau $A$ : Is silicosis required for silica-associated lung cancer? Am J Ind Med 2000, 37:252-259.

42. Hnizdo E, Vallyathan V: Chronic obstructive pulmonary disease due to occupational exposure to silica dust: a review of epidemiological and pathological evidence. Occup Environ Med 2003, 60:237-243.

43. Steenland K, Goldsmith DF: Silica exposure and autoimmune diseases. Am $J$ Ind Med 1995, 28:603-608.

44. Haustein UF, Ziegler V, Herrmann K, Mehlhorn J, Schmidt C: Silica-induced scleroderma. J Am Acad Dermatol 1990, 22:444-448.

45. Warheit DB: Inhaled amorphous silica particulates: what do we know about their toxicological profiles? J Environ Pathol Toxicol Oncol 2001, 20(Suppl 1):133-141.

46. Volk H: The Health of Workers in A Plant Making Highly Dispersed Silica. Archives of Environmental Health 1960, 1:125-128.

47. Wilson RK, Stevens PM, Lovejoy HB, Bell ZG, Richie RC: Respiratory effects of inhaled amorphous silica. In Health effects of synthetic silica particulates. Edited by: Dunnom DD. American Society for Testing and Materials; 1981:185-198.

48. Vitums VC, Edwards MJ, Niles NR, Borman JO, Lowry RD: Pulmonary fibrosis from amorphous silica dust, a product of silica vapor. Arch Environ Health 1977, 32:62-68.

49. Merget R, Bauer T, Kupper HU, Philippou S, Bauer HD, Breitstadt R, Bruening T: Health hazards due to the inhalation of amorphous silica. Arch Toxicol 2002, 75:625-634

50. Arts JH, Muijser H, Duistermaat E, Junker K, Kuper CF: Five-day inhalation toxicity study of three types of synthetic amorphous silicas in Wistar rats and post-exposure evaluations for up to 3 months. Food Chem Toxicol 2007, 45:1856-1867.

51. Johnston CJ, Driscoll KE, Finkelstein JN, Baggs R, O'Reilly MA, Carter J, Gelein R, Oberdorster G: Pulmonary chemokine and mutagenic responses in rats after subchronic inhalation of amorphous and crystalline silica. Toxicol Sci 2000, 56:405-413.

52. Lee KP, Kelly DP: The pulmonary response and clearance of Ludox colloidal silica after a 4-week inhalation exposure in rats. Fundam Appl Toxicol 1992, 19:399-410.

53. Reuzel PG, Bruijntjes JP, Feron VJ, Woutersen RA: Subchronic inhalation toxicity of amorphous silicas and quartz dust in rats. Food Chem Toxicol 1991, 29:341-354.

54. Rosenbruch M: Inhalation of amorphous silica: morphological and morphometric evaluation of lung associated lymph nodes in rats. Exp Toxicol Pathol 1992, 44:10-14.

55. Castranova V, Vallyathan V, Wallace WE: Silica and Silica-Induced Lung Diseases Boca Raton, FL: CRC Press; 1996.

56. McLaughlin JK, Chow WH, Levy LS: Amorphous silica: a review of health effects from inhalation exposure with particular reference to cancer. $J$ Toxicol Environ Health 1997, 50:553-566.

57. Peretz A, Checkoway H, Kaufman JD, Trajber I, Lerman Y: Silica, silicosis, and lung cancer. Isr Med Assoc J 2006, 8:114-118.

58. Huaux F: New developments in the understanding of immunology in silicosis. Curr Opin Allergy Clin Immunol 2007, 7:168-173.

59. Hamilton RF, Thakur SA, Holian A: Silica binding and toxicity in alveolar macrophages. Free Radic Biol Med 2008, 44:1246-1258.

60. Fubini $B$, Hubbard A: Reactive oxygen species (ROS) and reactive nitrogen species (RNS) generation by silica in inflammation and fibrosis. Free Radic Biol Med 2003, 34:1507-1516.

61. Shi X, Mao Y, Daniel LN, Saffiotti U, Dalal NS, Vallyathan V: Generation of reactive oxygen species by quartz particles and its implication for cellular damage. Applied Occupational and Environmental Hygiene 1995, 10:1138-1144

62. Merchant RK, Peterson MW, Hunninghake GW: Silica directly increases permeability of alveolar epithelial cells. J Appl Physiol 1990, 68:1354-1359.

63. Chen J, Armstrong LC, Liu SJ, Gerriets JE, Last JA: Silica increases cytosolic free calcium ion concentration of alveolar macrophages in vitro. Toxicol Appl Pharmacol 1991, 111:211-220.

64. Schins RP, Duffin R, Hohr D, Knaapen AM, Shi T, Weishaupt C, Stone V, Donaldson K, Borm PJ: Surface modification of quartz inhibits toxicity, particle uptake, and oxidative DNA damage in human lung epithelial cells. Chem Res Toxicol 2002, 15:1166-1173.

65. Fanizza C, Ursini CL, Paba E, Ciervo A, Di FA, Maiello R, De SP, Cavallo D: Cytotoxicity and DNA-damage in human lung epithelial cells exposed to respirable alpha-quartz. Toxicol In Vitro 2007, 21:586-594.

66. Li Y, ZHU T, Guo X, Shang Y: Hydroxyl radicals induced by quartz particles in lung alveolar macrophages: the role of surface iron. Progress in Natural Science 2006, 16:1138-1144.

67. Shang $Y, Z H U$ T, Li Y, Zhao J: Size-dependent hydroxyl radicals generation induced by $\mathrm{SiO}_{2}$ ultra-fine particles: The role of surface iron Science in China Series B: Chemistry 2009, 52:1033-1041.

68. Ding M, Chen F, Shi X, Yucesoy B, Mossman B, Vallyathan V: Diseases caused by silica: mechanisms of injury and disease development. Int Immunopharmacol 2002, 2:173-182.

69. Castranova V: Signaling pathways controlling the production of inflammatory mediators in response to crystalline silica exposure: role of reactive oxygen/nitrogen species. Free Radic Biol Med 2004, 37:916-925

70. Lapp NL, Castranova V: How silicosis and coal workers' pneumoconiosis develop-a cellular assessment. Occup Med 1993, 8:35-56.

71. Vanhee D, Gosset P, Boitelle A, Wallaert B, Tonnel AB: Cytokines and cytokine network in silicosis and coal workers' pneumoconiosis. Eur Respir J 1995, 8:834-842.

72. Piguet PF, Collart MA, Grau GE, Sappino AP, Vassalli P: Requirement of tumour necrosis factor for development of silica-induced pulmonary fibrosis. Nature 1990, 344:245-247.

73. Hornung V, Bauernfeind F, Halle A, Samstad EO, Kono H, Rock KL, Fitzgerald KA, Latz E: Silica crystals and aluminum salts activate the NALP3 inflammasome through phagosomal destabilization. Nat Immunol 2008, 9:847-856.

74. Fubini B: Surface reactivity in the pathogenic response to particulates. Environ Health Perspect 1997, 105(Suppl 5):1013-1020.

75. Fenoglio I, Martra G, Coluccia S, Fubini B: Possible role of ascorbic acid in the oxidative damage induced by inhaled crystalline silica particles. Chem Res Toxicol 2000, 13:971-975.

76. Hemenway DR, Absher MP, Fubini B, Bolis V: What is the relationship between hemolytic potential and fibrogenicity of mineral dusts? Arch Environ Health 1993, 48:343-347.

77. Pandurangi RS, Seehra MS, Razzaboni BL, Bolsaitis P: Surface and bulk infrared modes of crystalline and amorphous silica particles: a study of the relation of surface structure to cytotoxicity of respirable silica. Environ Health Perspect 1990, 86:327-336.

78. Murashov V, Harper M, Demchuk E: Impact of silanol surface density on the toxicity of silica aerosols measured by erythrocyte haemolysis. J Occup Environ Hyg 2006, 3:718-723.

79. Daniel LN, Mao Y, Williams AO, Saffiotti U: Direct interaction between crystalline silica and DNA - a proposed model for silica carcinogenesis. Scand J Work Environ Health 1995, 21(Suppl 2):22-26.

80. Fubini B, Zanetti G, Altilia S, Tiozzo R, Lison D, Saffiotti U: Relationship between surface properties and cellular responses to crystalline silica: studies with heat-treated cristobalite. Chem Res Toxicol 1999, 12:737-745.

81. Elias Z, Poirot O, Daniere MC, Terzetti F, Marande AM, Dzwigaj S, Pezerat H, Fenoglio I, Fubini B: Cytotoxic and transforming effects of silica particles with different surface properties in Syrian hamster embryo (SHE) cells. Toxicol In Vitro 2000, 14:409-422.

82. Bagchi N: What makes silica toxic? Br J Ind Med 1992, 49:163-166.

83. Ghiazza M, Gazzano E, Bonelli B, Fenoglio I, Polimeni M, Ghigo D, Garrone E, Fubini B: Formation of a vitreous phase at the surface of some commercial diatomaceous earth prevents the onset of oxidative stress effects. Chem Res Toxicol 2009, 22:136-145.

84. Donaldson K, Borm PJ: The quartz hazard: a variable entity. Ann Occup Hyg 1998, 42:287-294. 
85. Bye E, Davies R, Griffiths DM, Gylseth B, Moncrieff CB: In vitro cytotoxicity and quantitative silica analysis of diatomaceous earth products. $\mathrm{Br} J$ Ind Med 1984, 41:228-234.

86. Roelofs F, Vogelsberger W: Dissolution kinetics of synthetic amorphous silica in biological-like media and its theoretical description. J Physic Chem B 2004, 108:11308-11316.

87. Borm P, Klaessig FC, Landry TD, Moudgil B, Pauluhn J, Thomas K, Trottier R, Wood S: Research strategies for safety evaluation of nanomaterials, part V: role of dissolution in biological fate and effects of nanoscale particles. Toxicol Sci 2006, 90:23-32.

88. Limbach LK, Wick P, Manser P, Grass RN, Bruinink A, Stark WJ: Exposure of engineered nanoparticles to human lung epithelial cells: influence of chemical composition and catalytic activity on oxidative stress. Environ Sci Technol 2007, 41:4158-4163.

89. Borm PJ: Particle toxicology: from coal mining to nanotechnology. Inhal Toxicol 2002, 14:311-324.

90. Colvin VL: The potential environmental impact of engineered nanomaterials. Nat Biotechnol 2003, 21:1166-1170.

91. Oberdorster $\mathrm{G}$, Utell MJ: Ultrafine particles in the urban air: to the respiratory tract-and beyond? Environ Health Perspect 2002, 110 A440-A441.

92. Aillon KL, Xie Y, El-Gendy N, Berkland CJ, Forrest ML: Effects of nanomaterial physicochemical properties on in vivo toxicity. Adv Drug Deliv Rev 2009, 61:457-466.

93. Auffan M, Rose J, Bottero JY, Lowry GV, Jolivet JP, Wiesner MR: Towards a definition of inorganic nanoparticles from an environmental, health and safety perspective. Nature Nanotechnology 2009, 4:634-641

94. Hillegass JM, Shukla A, Lathrop SA, MacPherson MB, Fukagawa NK, Mossman BT: Assessing nanotoxicity in cells in vitro. Wiley Interdiscip Rev Nanomed Nanobiotechnol 2010, 2:219-231.

95. Li XY, Brown D, Smith S, MacNee W, Donaldson K: Short-term inflammatory responses following intratracheal instillation of fine and ultrafine carbon black in rats. Inhal Toxicol 1999, 11:709-731.

96. Nemmar A, Hoylaerts MF, Hoet PH, Vermylen J, Nemery B: Size effect of intratracheally instilled particles on pulmonary inflammation and vascular thrombosis. Toxicol Appl Pharmacol 2003, 186:38-45.

97. Zhang Q, Kusaka Y, Zhu X, Sato K, Mo Y, Kluz T, Donaldson K: Comparative toxicity of standard nickel and ultrafine nickel in lung after intratracheal instillation. J Occup Health 2003, 45:23-30

98. Kaewamatawong T, Kawamura N, Okajima M, Sawada M, Morita T, Shimada A: Acute pulmonary toxicity caused by exposure to colloidal silica: particle size dependent pathological changes in mice. Toxicol Pathol 2005, 33:743-749.

99. Wang JJ, Sanderson BJ, Wang H: Cytotoxicity and genotoxicity of ultrafine crystalline $\mathrm{SiO} 2$ particulate in cultured human lymphoblastoid cells. Environ Mol Mutagen 2007, 48:151-157.

100. Chen $M$, von Mikecz A: Formation of nucleoplasmic protein aggregates impairs nuclear function in response to $\mathrm{SiO} 2$ nanoparticles. Exp Cell Res 2005, 305:51-62.

101. Jin Y, Kannan S, Wu M, Zhao JX: Toxicity of luminescent silica nanoparticles to living cells. Chem Res Toxicol 2007, 20:1126-1133.

102. Lin W, Huang YW, Zhou XD, Ma Y: In vitro toxicity of silica nanoparticles in human lung cancer cells. Toxicol Appl Pharmacol 2006, 217:252-259.

103. Wottrich R, Diabate S, Krug HF: Biological effects of ultrafine model particles in human macrophages and epithelial cells in mono- and coculture. Int J Hyg Environ Health 2004, 207:353-361.

104. Choi SJ, Oh JM, Choy JH: Toxicological effects of inorganic nanoparticles on human lung cancer A549 cells. J Inorg Biochem 2009, 103:463-471.

105. Akhtar MJ, Ahamed M, Kumar S, Siddiqui H, Patil G, Ashquin M, Ahmad I: Nanotoxicity of pure silica mediated through oxidant generation rather than glutathione depletion in human lung epithelial cells. Toxicology 2010, 276:95-102.

106. Eom HJ, Choi J: Oxidative stress of silica nanoparticles in human bronchial epithelial cell, Beas-2B. Toxicol In Vitro 2009, 23:1326-1332.

107. Shi Y, Yadav S, Wang F, Wang H: Endotoxin promotes adverse effects of amorphous silica nanoparticles on lung epithelial cells in vitro. J Toxicol Environ Health A 2010, 73:748-756.

108. Yu KO, Grabinski CM, Schrand AM, Murdock RC, Wang W, Gu B, Schlager JJ, Hussain SM: Toxicity of amorphous silica nanoparticles in mouse keratinocytes. Journal of Nanoparticle Research 2009, 11:15-24.
109. Nabeshi H, Yoshikawa T, Matsuyama K, Nakazato Y, Arimori A, Isobe M, Tochigi S, Kondoh S, Hirai T, Akase T, Yamashita T, Yamashita K, Yoshida T, Nagano K, Abe Y, Yoshioka Y, Kamada H, Imazawa T, Itoh N, Tsunoda S, Tsutsumi Y: Size-dependent cytotoxic effects of amorphous silica nanoparticles on Langerhans cells. Pharmazie 2010, 65:199-201.

110. Yang $X$, Liu J, He H, Zhou L, Gong C, Wang X, Yang L, Yuan J, Huang H, He $L$, Zhang $B$, Zhuang $\mathrm{Z}: \mathrm{SiO}_{2}$ nanoparticles induce cytotoxicity and protein expression alteration in HaCaT cells. Part Fibre Toxicol 2010, 7:1.

111. Gong C, Tao G, Yang L, Liu J, Liu Q, Zhuang Z: SiO(2) nanoparticles induce global genomic hypomethylation in HaCaT cells. Biochem Biophys Res Commun 2010, 397:397-400.

112. Cousins BG, Doherty PJ, Williams RL, Fink J, Garvey MJ: The effect of silica nanoparticulate coatings on cellular response. J Mater Sci Mater Med 2004, 15:355-359.

113. Chang JS, Chang KL, Hwang DF, Kong ZL: In vitro cytotoxicitiy of silica nanoparticles at high concentrations strongly depends on the metabolic activity type of the cell line. Environ Sci Technol 2007, 41:2064-2068.

114. Yang $H, W u ~ Q$, Tang $M$, Kong $L$, Lu Z: Cell membrane injury induced by silica nanoparticles in mouse macrophage. J Biomed Nanotechnol 2009, 5:528-535.

115. Gerloff K, Albrecht C, Boots AW, Forster I, Schins RPF: Cytotoxicity and oxidative DNA damage by nanoparticles in human intestinal Caco-2 cells. Nanotoxicology 2009, 3:355-364.

116. Ye Y, Liu J, Xu J, Sun L, Chen M, Lan M: Nano-SiO2 induces apoptosis via activation of $\mathrm{p} 53$ and Bax mediated by oxidative stress in human hepatic cell line. Toxicol In Vitro 2010, 24:751-758.

117. Peters K, Unger RE, Kirkpatrick CJ, Gatti AM, Monari E: Effects of nanoscaled particles on endothelial cell function in vitro: studies on viability, proliferation and inflammation. J Mater Sci Mater Med 2004, 15:321-325.

118. Napierska D, Thomassen LC, Rabolli V, Lison D, Gonzalez L, Kirsch-Volders M, Martens JA, Hoet PH: Size-dependent cytotoxicity of monodisperse silica nanoparticles in human endothelial cells. Small 2009, 5:846-853.

119. Ye YY, Liu JW, Chen MC, Sun LJ, Lan MB: In vitro toxicity of silica nanoparticles in myocardial cells. Environmental Toxicology and Pharmacology 2010, 29:131-137.

120. Barnes CA, Elsaesser A, Arkusz J, Smok A, Palus J, Lesniak A, Salvati A, Hanrahan JP, Jong WH, Dziubaltowska E, Stepnik M, Rydzynski K, McKerr G, Lynch I, Dawson KA, Howard CV: Reproducible comet assay of amorphous silica nanoparticles detects no genotoxicity. Nano Lett 2008, 8:3069-3074.

121. Gonzales L, Lison D, Kirsch-Volders M: Genotoxicity of engineered nanomaterials: A critical review. Nanotoxicology 2008, 2:252-273.

122. Gonzalez L, Thomassen LCJ, Plas G, Rabolli V, Napierska D, Decordier I, Roelants M, Hoet PH, Kirschhock CEA, Martens JA, Lison D, Kirsch-Volders M: Exploring the aneugenic and clastogenic potential in the nanosize range: A549 human lung carcinoma cells and amorphous monodisperse silica nanoparticles as models. Nanotoxicology 2010, 4:382-395.

123. Lin YS, Tsai CP, Huang HY, Kuo CT, Hung Y, Huang DM, Chen YC, Mou CY: Well-Ordered Mesoporous Silica Nanoparticles as Cell Markers. Chemistry of Materials 2005, 17:4570-4573.

124. Vallet-Regi M: Nanostructured mesoporous silica matrices in nanomedicine. Journal of Internal Medicine 2010, 267:22-43.

125. Chung TH, Wu SH, Yao M, Lu CW, Lin YS, Hung Y, Mou CY, Chen YC, Huang DM: The effect of surface charge on the uptake and biological function of mesoporous silica nanoparticles in 3T3-L1 cells and human mesenchymal stem cells. Biomaterials 2007, 28:2959-2966.

126. Fisichella M, Dabboue H, Bhattacharyya S, Saboungi ML, Salvetat JP, Hevor T, Guerin M: Mesoporous silica nanoparticles enhance MTT formazan exocytosis in HeLa cells and astrocytes. Toxicol In Vitro 2009, 23:697-703.

127. Giri S, Trewyn BG, Stellmaker MP, Lin VS: Stimuli-responsive controlledrelease delivery system based on mesoporous silica nanorods capped with magnetic nanoparticles. Angew Chem Int Ed Engl 2005, 44:5038-5044.

128. Lu F, Wu SH, Hung Y, Mou CY: Size effect on cell uptake in wellsuspended, uniform mesoporous silica nanoparticles. Small 2009 5:1408-1413.

129. Lu J, Liong M, Zink Jl, Tamanoi F: Mesoporous silica nanoparticles as a delivery system for hydrophobic anticancer drugs. Small 2007, 3:1341-1346. 
130. Slowing I, Trewyn BG, Lin VS: Effect of surface functionalization of MCM41-type mesoporous silica nanoparticles on the endocytosis by human cancer cells. J Am Chem Soc 2006, 128:14792-14793.

131. Slowing II, Wu CW, Vivero-Escoto JL, Lin VS: Mesoporous silica nanoparticles for reducing hemolytic activity towards mammalian red blood cells. Small 2009, 5:57-62.

132. Tao Z, Morrow MP, Asefa T, Sharma KK, Duncan C, Anan A, Penefsky HS, Goodisman J, Souid AK: Mesoporous silica nanoparticles inhibit cellular respiration. Nano Lett 2008, 8:1517-1526.

133. Di Pasqua AJ, Sharma KK, Shi YL, Toms BB, Ouellette W, Dabrowiak JC, Asefa T: Cytotoxicity of mesoporous silica nanomaterials. J Inorg Biochem 2008, 102:1416-1423.

134. Vallhov H, Gabrielsson S, Stromme M, Scheynius A, Garcia-Bennett AE: Mesoporous silica particles induce size dependent effects on human dendritic cells. Nano Lett 2007, 7:3576-3582.

135. He Q, Zhang Z, Gao Y, Shi J, Li Y: Intracellular localization and cytotoxicity of spherical mesoporous silica nano- and microparticles. Small 2009, 5:2722-2729.

136. Brown SC, Kamal M, Nasreen N, Baumuratov A, Sharma P, Antony VB, Moudgil BM: Influence of shape, adhesion and simulated lung mechanics on amorphous silica nanoparticle toxicity. Advanced Powder Technology 2007, 18:69-79.

137. Diaz B, Sanchez-Espinel C, Arruebo M, Faro J, de ME, Magadan S, Yague C, Fernandez-Pacheco R, Ibarra MR, Santamaria J, Gonzalez-Fernandez A: Assessing methods for blood cell cytotoxic responses to inorganic nanoparticles and nanoparticle aggregates. Small 2008, 4:2025-2034

138. Herseth J, Refsnes M, Lag M, Hetland G, Schwarze P: IL-1 beta as a determinant in silica-induced cytokine responses in monocyteendothelial cell co-cultures. Hum Exp Toxicol 2008, 27:387-399.

139. Herseth Jl, Volden V, Schwarze PE, Lag M, Refsnes M: IL-1 beta differently involved in IL-8 and FGF-2 release in crystalline silica-treated lung cell co-cultures. Part Fibre Toxicol 2008, 5:16.

140. Sohaebuddin SK, Thevenot PT, Baker D, Eaton JW, Tang L: Nanomaterial cytotoxicity is composition, size, and cell type dependent. Part Fibre Toxicol 2010, 7:22.

141. Rabolli V, Thomassen LCJ, Princen C, Napierska D, Gonzalez L, KirschVolders M, Hoet PH, Huaux F, Kirschhock CEA, Martens JA, Lison D: Influence of size, surface area and microporosity on the in vitro cytotoxic activity of amorphous silica nanoparticles in different cell types. Nanotoxicology 2010, 4:307-318.

142. Donaldson K, Stone V, Clouter A, Renwick L, MacNee W: Ultrafine particles. Occup Environ Med 2001, 58:211-6, 199.

143. Warheit DB, Carakostas MC, Kelly DP, Hartsky MA: Four-week inhalation toxicity study with Ludox colloidal silica in rats: pulmonary cellular responses. Fundam Appl Toxicol 1991, 16:590-601.

144. Cho WS, Choi M, Han BS, Cho M, Oh J, Park K, Kim SJ, Kim SH, Jeong J: Inflammatory mediators induced by intratracheal instillation of ultrafine amorphous silica particles. Toxicol Lett 2007, 175:24-33.

145. Chen Z, Meng H, Xing G, Yuan H, Zhao F, Liu R, Chang X, Gao X, Wang T, Jia G, Ye C, Chai Z, Zhao Y: Age-related differences in pulmonary and cardiovascular responses to $\mathrm{SiO} 2$ nanoparticle inhalation: nanotoxicity has susceptible population. Environ Sci Technol 2008, 42:8985-8992.

146. Kaewamatawong T, Shimada A, Okajima M, Inoue H, Morita T, Inoue K, Takano H: Acute and subacute pulmonary toxicity of low dose of ultrafine colloidal silica particles in mice after intratracheal instillation. Toxicol Pathol 2006, 34:958-965

147. Chen Y, Chen J, Dong J, Jin Y: Comparing study of the effect of nanosized silicon dioxide and microsized silicon dioxide on fibrogenesis in rats. Toxicol Ind Health 2004, 20:21-27.

148. Warheit DB, Webb TR, Colvin VL, Reed KL, Sayes CM: Pulmonary bioassay studies with nanoscale and fine-quartz particles in rats: toxicity is not dependent upon particle size but on surface characteristics. Toxicol Sci 2007, 95:270-280.

149. Sayes CM, Reed KL, Glover KP, Swain KA, Ostraat ML, Donner EM, Warheit DB: Changing the dose metric for inhalation toxicity studies: short-term study in rats with engineered aerosolized amorphous silica nanoparticles. Inhal Toxicol 2010, 22:348-354.

150. Dong CC, Yin XJ, Ma JY, Millecchia L, Barger MW, Roberts JR, Zhang XD, Antonini JM, Ma JK: Exposure of brown Norway rats to diesel exhaust particles prior to ovalbumin (OVA) sensitization elicits IgE adjuvant activity but attenuates OVA-induced airway inflammation. Toxicol Sci 2005, 88:150-160.

151. Lambert AL, Dong W, Selgrade MK, Gilmour MI: Enhanced allergic sensitization by residual oil fly ash particles is mediated by soluble metal constituents. Toxicol Appl Pharmacol 2000, 165:84-93.

152. Steerenberg PA, Withagen CE, Dormans JA, van Dalen WJ, van LH, Casee FR: Adjuvant activity of various diesel exhaust and ambient particles in two allergic models. J Toxicol Environ Health A 2003, 66:1421-1439.

153. Arts JH, Schijf MA, Kuper CF: Preexposure to amorphous silica particles attenuates but also enhances allergic reactions in trimellitic anhydridesensitized brown Norway rats. Inhal Toxicol 2008, 20:935-948.

154. So SJ, Jang IS, Han CS: Effect of Micro/Nano Silica Particle Feeding for Mice. Journal of Nanoscience and Nanotechnology 2008, 8:5367-5371.

155. Kumar R, Roy I, Ohulchanskky TY, Vathy LA, Bergey EJ, Sajjad M, Prasad PN: In vivo biodistribution and clearance studies using multimodal organically modified silica nanoparticles. ACS Nano 2010, 4:699-708.

156. Hudson SP, Padera RF, Langer R, Kohane DS: The biocompatibility of mesoporous silicates. Biomaterials 2008, 29:4045-4055.

157. Nishimori H, Kondoh M, Isoda K, Tsunoda S, Tsutsumi Y, Yagi K: Silica nanoparticles as hepatotoxicants. European Journal of Pharmaceutics and Biopharmaceutics 2009, 72:496-501.

158. Cho M, Cho WS, Choi M, Kim SJ, Han BS, Kim SH, Kim HO, Sheen YY, Jeong J: The impact of size on tissue distribution and elimination by single intravenous injection of silica nanoparticles. Toxicol Lett 2009, 189:177-183.

159. Park EJ, Park K: Oxidative stress and pro-inflammatory responses induced by silica nanoparticles in vivo and in vitro. Toxicol Lett 2009, 184:18-25.

160. Kim HW, Ahn EK, Jee BK, Yoon HK, Lee KH, Lim Y: Nanoparticulate-induced toxicity and related mechanism in vitro and in vivo. Journal of Nanoparticle Research 2009, 11:55-65.

161. Sayes CM, Reed KL, Warheit DB: Assessing toxicity of fine and nanoparticles: comparing in vitro measurements to in vivo pulmonary toxicity profiles. Toxicol Sci 2007, 97:163-180.

162. Lu S, Duffin R, Poland C, Daly P, Murphy F, Drost E, MacNee W, Stone V, Donaldson K: Efficacy of simple short-term in vitro assays for predicting the potential of metal oxide nanoparticles to cause pulmonary inflammation. Environ Health Perspect 2009, 117:241-247.

163. Rushton EK, Jiang J, Leonard SS, Eberly S, Castranova V, Biswas P, Elder A, Han X, Gelein R, Finkelstein J, Oberdorster G: Concept of assessing nanoparticle hazards considering nanoparticle dosemetric and chemical/ biological response metrics. J Toxicol Environ Health A 2010, 73:445-461.

164. Brandenberger C, Rothen-Rutishauser B, Muhlfeld C, Schmid O, Ferron GA, Maier KL, Gehr P, Lenz AG: Effects and uptake of gold nanoparticles deposited at the air-liquid interface of a human epithelial airway model. Toxicol Appl Pharmacol 2010, 242:56-65.

165. Saffiotti U: Lung cancer induction by crystalline silica. Prog Clin Biol Res 1992, 374:51-69.

166. Waters KM, Masiello LM, Zangar RC, Tarasevich BJ, Karin NJ, Quesenberry RD, Bandyopadhyay S, Teeguarden JG, Pounds JG, Thrall BD: Macrophage responses to silica nanoparticles are highly conserved across particle sizes. Toxicol Sci 2009, 107:553-569.

167. Ehrenberg MS, Friedman AE, Finkelstein JN, Oberdorster G, McGrath JL: The influence of protein adsorption on nanoparticle association with cultured endothelial cells. Biomaterials 2009, 30:603-610.

168. Horie M, Nishio K, Fujita K, Endoh S, Miyauchi A, Saito Y, Iwahashi $H_{\text {, }}$ Yamamoto K, Murayama H, Nakano H, Nanashima N, Niki E, Yoshida Y: Protein Adsorption of Ultrafine Metal Oxide and Its Influence on Cytotoxicity toward Cultured Cells. Chem Res Toxicol 2009, 22:543-553.

169. Shang W, Nuffer JH, Muniz-Papandrea VA, Colon W, Siegel RW, Dordick JS: Cytochrome $C$ on silica nanoparticles: influence of nanoparticle size on protein structure, stability, and activity. Small 2009, 5:470-476.

170. Lundqvist M, Sethson I, Jonsson BH: Protein adsorption onto silica nanoparticles: conformational changes depend on the particles' curvature and the protein stability. Langmuir 2004, 20:10639-10647.

171. Vertegel AA, Siegel RW, Dordick JS: Silica nanoparticle size influences the structure and enzymatic activity of adsorbed lysozyme. Langmuir 2004, 20:6800-6807.

172. Rossi EM, Pylkkanen L, Koivisto AJ, Vippola M, Jensen KA, Miettinen M, Sirola K, Nykasenoja H, Karisola P, Stjernvall T, Vanhala E, Kiilunen M, Pasanen P, Makinen M, Hameri K, Joutsensaari J, Tuomi T, Jokiniemi J, 
Wolff H, Savolainen K, Matikainen S, Alenius H: Airway exposure to silicacoated TiO2 nanoparticles induces pulmonary neutrophilia in mice. Toxicol Sci 2010, 113:422-433.

173. Sayes CM, Warheit DB: Characterization of nanomaterials for toxicity assessment. Wiley Interdiscip Rev Nanomed Nanobiotechnol 2009, 1:660-670.

174. Geys J, Nemery B, Hoet PH: Assay conditions can influence the outcome of cytotoxicity tests of nanomaterials: better assay characterization is needed to compare studies. Toxicol In Vitro 2010, 24:620-629.

175. Monteiro-Riviere NA, Inman AO, Zhang LW: Limitations and relative utility of screening assays to assess engineered nanoparticle toxicity in a human cell line. Toxicol Appl Pharmacol 2009, 234:222-235.

176. Murdock RC, Braydich-Stolle L, Schrand AM, Schlager JJ, Hussain SM: Characterization of nanomaterial dispersion in solution prior to in vitro exposure using dynamic light scattering technique. Toxicol Sci 2008, 101:239-253.

177. Brinker CF, Schrerer GW: Sol-Gel Science. The Physics and Chemistry of Sol-Gel Processing. 2 edition. London: Academic Press; 1990.

178. Momma K, Izumi F: VESTA: a three-dimensional visualization system for electronic and structural analysis. Journal of Applied Crystallography 2008, 41:653-658.

doi:10.1186/1743-8977-7-39

Cite this article as: Napierska et al.: The nanosilica hazard: another variable entity. Particle and Fibre Toxicology 2010 7:39.

\section{Submit your next manuscript to BioMed Central} and take full advantage of:

- Convenient online submission

- Thorough peer review

- No space constraints or color figure charges

- Immediate publication on acceptance

- Inclusion in PubMed, CAS, Scopus and Google Scholar

- Research which is freely available for redistribution

Submit your manuscript at www.biomedcentral.com/submit 